OPEN ACCESS

Edited by:

Andres Fullana,

University of Alicante, Spain

Reviewed by:

Xiaoguang Duan,

Curtin University, Australia Jiguang Deng,

Beijing University of Technology, China

${ }^{*}$ Correspondence: Fengbao Zhang

fbzhang@tju.edu.cn

Wenchao Peng

wenchao.peng@tju.edu.cn

Specialty section:

This article was submitted to Green and Environmental Chemistry,

a section of the journa

Frontiers in Chemistry

Received: 06 September 2017 Accepted: 06 October 2017

Published: 31 October 2017

Citation: Han W, Li Z, Li Y, Fan X, Zhang F, Zhang $G$ and Peng W (2017) The Promoting Role of Different Carbon

Allotropes Cocatalysts for Semiconductors in Photocatalytic Energy Generation and Pollutants Degradation. Front. Chem. 5:84 doi: 10.3389/fchem.2017.00084

\section{The Promoting Role of Different Carbon Allotropes Cocatalysts for Semiconductors in Photocatalytic Energy Generation and Pollutants Degradation}

\author{
Weiwei Han, Zhen Li, Yang Li, Xiaobin Fan, Fengbao Zhang*, Guoliang Zhang and \\ Wenchao Peng*
}

School of Chemical Engineering and Technology, Tianjin University, Tianjin, China

Semiconductor based photocatalytic process is of great potential for solving the fossil fuels depletion and environmental pollution. Loading cocatalysts for the modification of semiconductors could increase the separation efficiency of the photogenerated hole-electron pairs, enhance the light absorption ability of semiconductors, and thus obtain new composite photocatalysts with high activities. Kinds of carbon allotropes, such as activated carbon, carbon nanotubes, graphene, and carbon quantum dots have been used as effective cocatalysts to enhance the photocatalytic activities of semiconductors, making them widely used for photocatalytic energy generation, and pollutants degradation. This review focuses on the loading of different carbon allotropes as cocatalysts in photocatalysis, and summarizes the recent progress of carbon materials based photocatalysts, including their synthesis methods, the typical applications, and the activity enhancement mechanism. Moreover, the cocatalytic effect among these carbon cocatalysts is also compared for different applications. We believe that our work can provide enriched information to harvest the excellent special properties of carbon materials as a platform to develop more efficient photocatalysts for solar energy utilization.

Keywords: carbon allotropes, semiconductor, photocatalysis, cocatalysts, energy generation, pollutants degradation

\section{INTRODUCTION}

Environmental pollution and fossil fuels depletion are the most serious social problems nowadays. Since the discovery of the photocatalytic splitting of water on $\mathrm{TiO}_{2}$ electrodes by Fujishima and Honda in 1972, photocatalysis technology has become one of the most promising technologies for energy generation and environment remediation (Fujishima and Honda, 1972). Moreover, solar energy is clean, sustainable, and inexhaustible, which is therefore the most hopeful resource to solve the energy and environment problems (Chen et al., 2010a). Mostly, photocatalysis is a semiconductor-mediated process (Chen et al., 2010b; Wang et al., 2014; Zhang et al., 2016b). So far, kinds of semiconductor materials, including metal oxides, metal sulfides and metal containing salts have been used as photocatalysts. Some metal free materials, such as silicon, sulfur, graphic 
carbon nitride $\left(\mathrm{g}-\mathrm{C}_{3} \mathrm{~N}_{4}\right)$, have also been developed as photocatalysts for the utilization of sunlight (Peng et al., 2013; Cao and Yu, 2014; Devi and ArunaKumari, 2014; He et al., 2015). However, some fundamental problems must be resolved before their real application, which are (1) low utilization efficiency of solar energy; (2) poor quantum efficiency; (3) severe photo corrosion (Zhang and Guo, 2013; Chowdhury and Balasubramanian, 2014; Han et al., 2015; Xie et al., 2015; Liu Y. et al., 2017b). To address these obstacles, modification of semiconductors with suitable cocatalysts is a frequent and effective solution (Yang J. H. et al., 2013). Metal nanoparticles and their compounds, especially noble metal based materials, are always used as cocatalysts (Bai et al., 2014; Zhang et al., 2015a; Zhong et al., 2016). Although they are effective to enhance the photocatalytic activity, the high cost and rare storage on earth limit their practical application (Ran et al., 2014). To develop cheap, highly efficient alternatives to replace noble metal based cocatalysts is still a great challenge in the photocatalysis filed.

Recently, carbon materials, including activated carbon (AC), fullerenes $\left(\mathrm{C}_{60}\right)$, carbon nanotubes (CNTs), graphene $(\mathrm{GR})$, and other carbon allotropes, have been widely investigated as cocatalysts for semiconductors in photocatalysis (Xiang et al., 2012; Ouzzine et al., 2014; Cao and Yu, 2016; Paulo et al., 2016; Yu et al., 2016). Specially, CNTs and GR have large specific surface areas (SSAs), excellent electric conductivity, high mechanical strength, and good thermal, and chemical stability, making them ideal substitute for noble metal cocatalysts (Zhang et al., 2012; Wang et al., 2013, 2017; Di et al., 2015; Han et al., 2016). Figure 1 shows the structure models of the carbon materials and their photocatalytic applications as cocatalysts simply. Many kinds of carbon cocatalysts based composites have been reported for photocatalytic reactions, and the cocatalytic mechanisms have also been discussed (Woan et al., 2009; Chen et al., 2011; Lee W. J. et al., 2012; Xie et al., 2013; Shearer et al., 2014; Li et al., 2015). For example, a graphene- $\mathrm{TiO}_{2}$ NPs hybrid was successfully synthesized by wrapping amorphous $\mathrm{TiO}_{2}$ NPs with GO using a one-step hydrothermal method by Lee and coworkers (Lee J. S. et al., 2012). The hybrid exhibited superior photocatalytic activity for the photodegradation of MB under the visible light irradiation. Fan et al. prepared a novel 3D AgX/graphene aerogels $(\mathrm{X}=\mathrm{Br}, \mathrm{Cl})$ structured composite, which exhibited excellent photocatalytic and cycling performance for the degradation of $\mathrm{MO}$ and reduction of $\mathrm{Cr}^{\mathrm{VI}}$ (Fan Y. et al., 2015). They also investigated photocatalytic enhancement mechanism of the graphene aerogels in the composite, which could effectively suppress the recombination of photogenerated holes, and electrons as a capable substrate for the photocatalyst. Tian et al. reported a new CQDs/hydrogenated $\mathrm{TiO}_{2}\left(\mathrm{H}-\mathrm{TiO}_{2}\right)$ photocatalyst by assembling CQDs on the surface of $\mathrm{H}_{-} \mathrm{TiO}_{2}$ (Tian et al., 2015). The photocatalytic activity of CQDs $/ \mathrm{H}-\mathrm{TiO}_{2}$ was superior to $\mathrm{P} 25, \mathrm{TiO}_{2}$ nanobelts, and $\mathrm{H}$ $\mathrm{TiO}_{2}$ nanobelts for the degradation of $\mathrm{MO}$ under UV-visible-NIR irradiation. The CQDs have excellent photo-induced electron transfer and reservoir properties, which could convert NIR light to visible light to be in full used by $\mathrm{H}-\mathrm{TiO}_{2}$ and effectively suppress the recombination of electron-hole pairs. Generally, loading carbon materials as cocatalysts for semiconductors, the

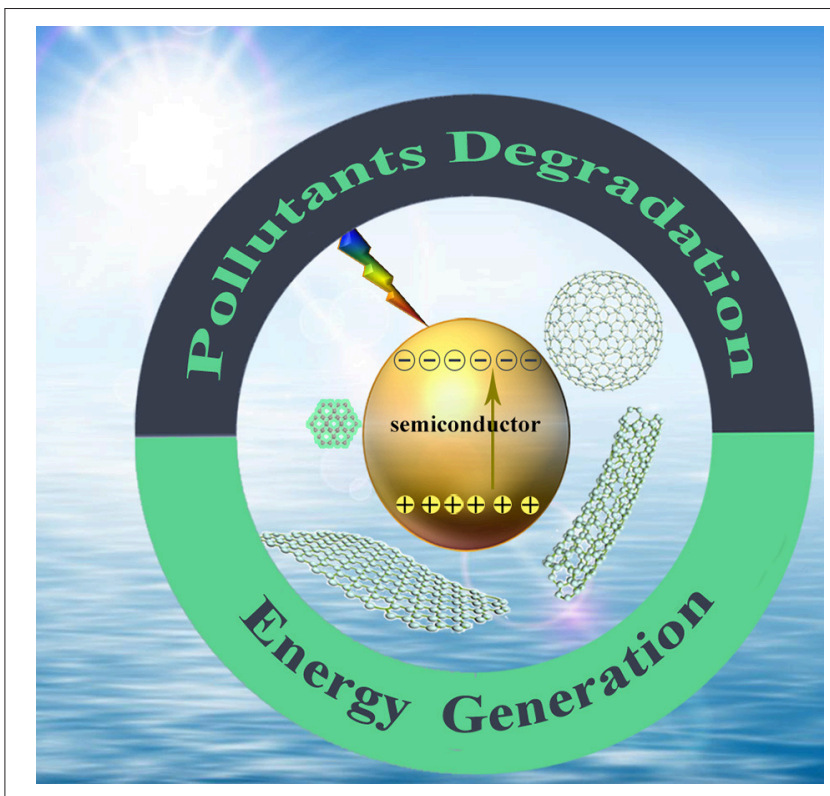

FIGURE 1 | Schematic illustration of the photocatalytic applications of carbon materials based semiconductor composites.

synergistic effect between them can increase the active sites, widen the absorption range of the solar light, facilitate the separation of the electron-hole pairs, and thus enhancing the photocatalytic activity.

To develop carbon materials based composite has attracted great attention for low cost and highly active photocatalysts. Lots of researches have been done on this subject, but a systematic summary about the key roles of different carbon allotropes as cocatalysts is still lacking. Herein, we aim to provide an overview on recent advances in the synthesis, multiple applications and mechanism of different carbon allotropes based composite photocatalysts. On behalf of this review, we wish more carbon based photocatalysts could be synthesized for environment remediation and energy generation.

\section{PHOTOCATALYSTS SYNTHESIS}

The synthesis process will affect the morphologies, properties and activities of the composite photocatalyts greatly. As shown in Table 1, we summarized the typical synthesis methods of the recently reported carbon based photocatalysts. The semiconductors could be loaded on carbon materials by one-step grinding, stirring, ultrasonic assisted dispersing or by some complicated multi-step synthesis methods. It can be concluded that mechanical mixing, hydrothermal/solvothemal, and sol-gel process are more frequently used. In addition, photocatalytic reduction and microwave-assisted method are also reported, and they may have a great potential due to the green and sustainable synthetic processes. 


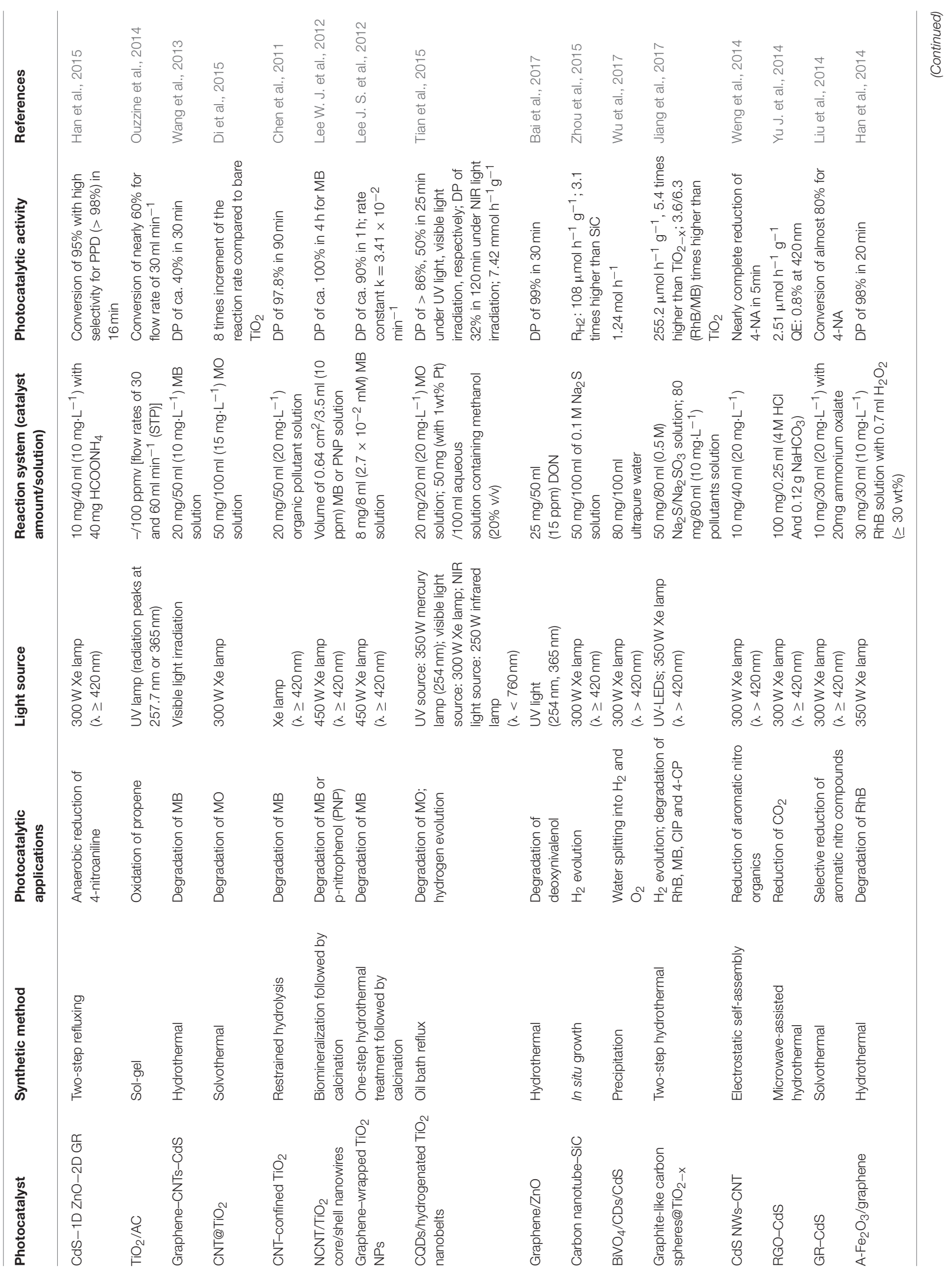




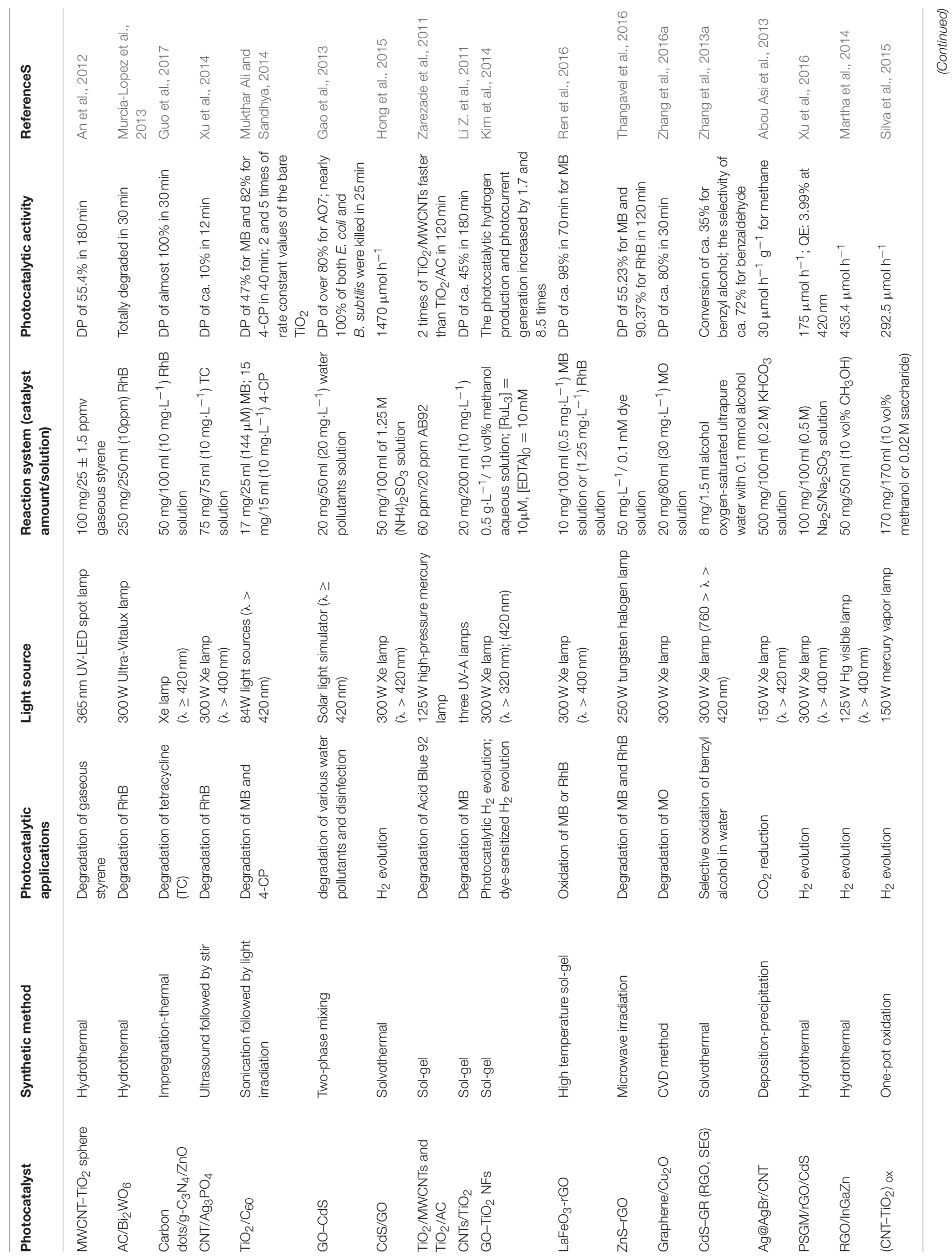




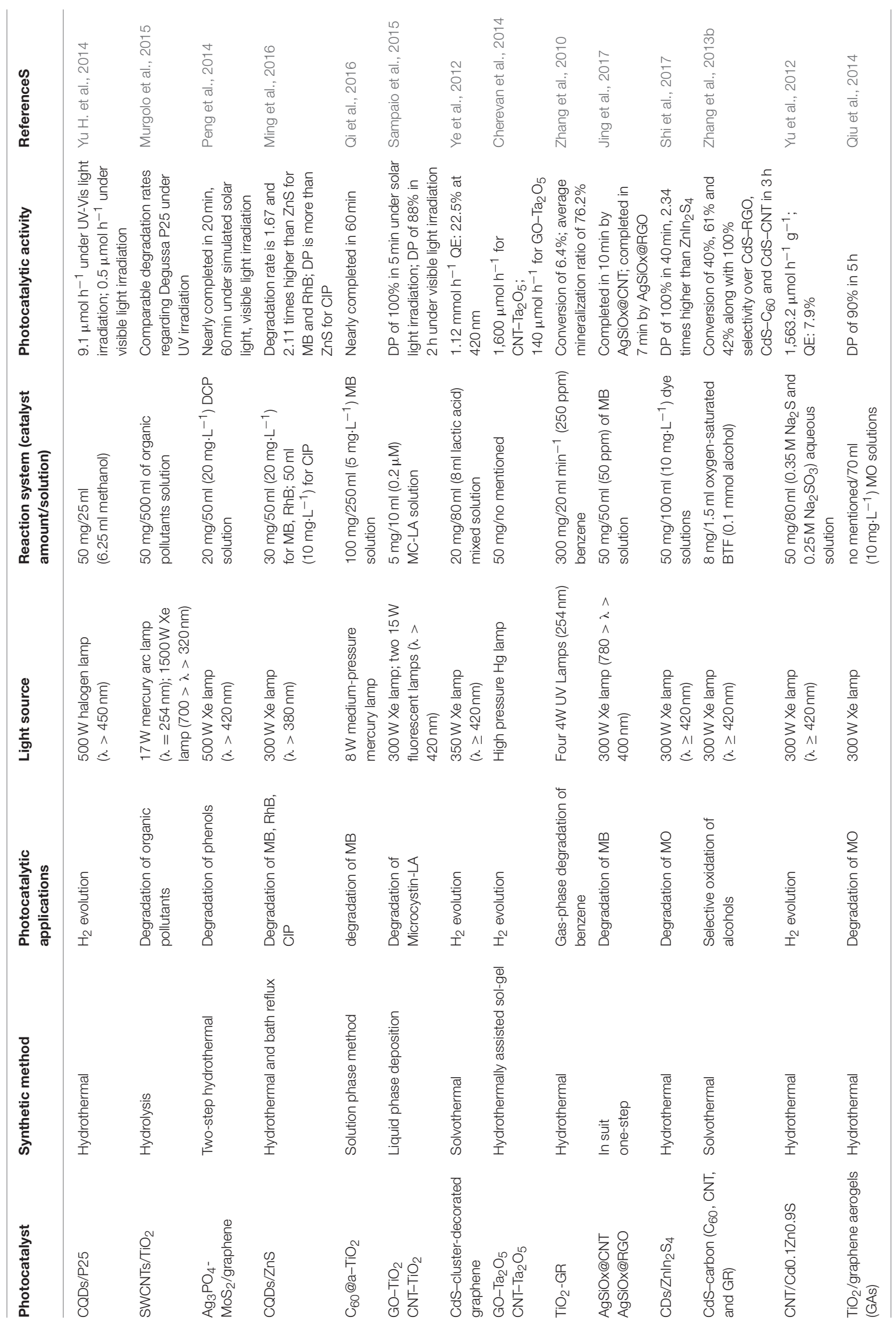




\section{Hydrothermal/Solvothemal Methods}

Hydrothermal or solvothermal methods are the most frequently used ways due to their mild reaction conditions, high product purity, controllable morphology, good crystallinity, and uniform distribution of obtained products (Li Q. et al., 2011). For example, Liu et al. synthesized GR-CdS nanocomposites by an one-step solvothermal method using DMSO as reductant and sulfure source (Liu et al., 2014). In the preparation procedure, GO was dispersed in DMSO to obtain the GO-DMSO dispersion, $\mathrm{Cd}\left(\mathrm{CH}_{3} \mathrm{COO}\right)_{2} \cdot 2 \mathrm{H}_{2} \mathrm{O}$ was then added. The mixture was then treated at $453 \mathrm{~K}$ for $12 \mathrm{~h}$ to obtain the final composites. The photocatalytic activity of GR-CdS nanocomposites for selective reduction of aromatic nitro compounds was dramatically enhanced compared to the pure CdS. This can be ascribed to the synergistic effect with graphene addition, the increased visible light absorption range and intensity, the improved lifetime and charge transfer ability, and the enhanced adsorption capacity of this nanocomposite toward the nitro compounds.

Han et al. synthesized $2 \mathrm{D}$ hexagonal $\alpha-\mathrm{Fe}_{2} \mathrm{O}_{3} /$ graphene nanoplate composites by a simple one-step hydrothermal method with no template (Han et al., 2014). Using hydrothermal method, not only the effective reduction of the GO to graphene was achieved, but intimate contact was also formed between the $\alpha-\mathrm{Fe}_{2} \mathrm{O}_{3}$ nanoplates and graphene. A significant enhancement for photocatalytic degradation of RhB could be observed after the combination with graphene cocatalyst. An et al. fabricated $\mathrm{MWCNT}-\mathrm{TiO}_{2}$ sphere composites by a facile one-step hydrothermal method using $\mathrm{TiF}_{4}$ as titanium source and CNTs as structure regulator (An et al., 2012). The effects of hydrothermal temperature and hydrothermal time on the structural characteristics of $\mathrm{MWCNT}-\mathrm{TiO}_{2}$ photocatalysts were investigated. Decreasing hydrothermal temperature or prolonging the hydrothermal time could lead to the enhancement of the photocatalytic degradation efficiency of both gaseous (i.e., styrene) and aqueous (i.e., MO) phase. Decreasing the hydrothermal temperature could lead to the crystallite size decrease of $\mathrm{TiO}_{2}$ (Table 2), while prolonging the hydrothermal time will increase the synergistic effects between $\mathrm{TiO}_{2}$ and MWCNTs, thus promoting the photocatalytic performance.

As reported by Murcia-López et al. the calcination could be applied after hydrothermal process to prepare the $\mathrm{AC} / \mathrm{Bi}_{2} \mathrm{WO}_{6}$ and $\mathrm{AC} / \mathrm{TiO}_{2} / \mathrm{Bi}_{2} \mathrm{WO}_{6}$ photocatalysts (Murcia-Lopez et al., 2013). The introduction of optimized percentage of AC (2 $\mathrm{wt} \%$ ) could form 3D-hierarchical structures of both $\mathrm{AC} / \mathrm{Bi}_{2} \mathrm{WO}_{6}$ and $\mathrm{AC} / \mathrm{TiO}_{2} / \mathrm{Bi}_{2} \mathrm{WO}_{6}$, which exhibited improved photocatalytic activities for the $\mathrm{RhB}$ degradation under both $\mathrm{UV}$-vis and visible illumination compared to pure $\mathrm{Bi}_{2} \mathrm{WO}_{6}$. Here, the presence of AC could stimulate the 3D-hierarchical structure formation, and will increase the surface area and absorption ability of the catalyst at the same time.

\section{Mechanical Mixing Method}

The loading of carbon cocatalysts can also be performed by simple mechanical mixing processes, such as magnetic stirring, ball milling, and ultrasonication (Xu et al., 2014; Guo et al., 2017). Ali et al. used $\mathrm{C}_{60}$ as cocatalysts for the modification of $\mathrm{TiO}_{2}$ using a simple sonication assisted mixing method (Mukthar Ali and Sandhya, 2014). The $\mathrm{C}_{60}$

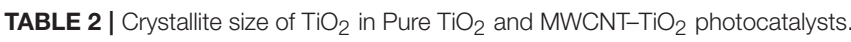

\begin{tabular}{|c|c|}
\hline Samples prepared under different conditions & Crystallite siz \\
\hline Pure $\mathrm{TiO}_{2}$ & 44.7 \\
\hline 7.2 wt \% MWCNTs & 33.1 \\
\hline 18.9 wt \% MWCNTs & 30.1 \\
\hline 31.7 wt \% MWCNTs & 29.9 \\
\hline 48.2wt \% MWCNTs & 30.6 \\
\hline 51.6 wt $\% \mathrm{TiO}_{2}$ & 23.2 \\
\hline 68.4 wt $\% \mathrm{TiO}_{2}$ & 26.7 \\
\hline 81.1 wt $\% \mathrm{TiO}_{2}$ & 30.1 \\
\hline 89.6 wt $\% \mathrm{TiO}_{2}$ & 35.2 \\
\hline $120^{\circ} \mathrm{C}$ & 24.2 \\
\hline $150^{\circ} \mathrm{C}$ & 26.7 \\
\hline $180^{\circ} \mathrm{C}$ & 27.3 \\
\hline $210^{\circ} \mathrm{C}$ & 28.4 \\
\hline $24 \mathrm{~h}$ & 25.5 \\
\hline $48 h$ & 26.5 \\
\hline $72 \mathrm{~h}$ & 26.7 \\
\hline
\end{tabular}

Reprinted from An et al. (2012), Copyright 2012, with permission from American Chemical Society.

molecules were first dispersed in $\beta$-cyclodextrin (CD), and then mixed with the suspension of $\mathrm{TiO}_{2}$ with the assistance of sonication under sunlight. According to the HRTEM images of the composites, $\mathrm{C}_{60}$ cocatalysts are dispersed in the composite without aggregation. They believed that the nonaggregated $\mathrm{C}_{60}$ cocatylysts played a key role in increasing the amount of reactive oxygen species (ROS) and suppressing photogenerated charge recombination, thus leading to the enhanced photocatalytic activity. The photocatalytic activity of the composite shows 2 and 5 times higher than the bare $\mathrm{TiO}_{2}$ for the degradation of $\mathrm{MB}$ and 4-CP, respectively. Gao and his coworkers successfully synthesized GO-CdS composites by a novel two-phase mixing method (Gao et al., 2013). By simply stirring for $24 \mathrm{~h}$, the two phases are mixed into a homogeneous solution, and CdS nanoparticles are then uniformly deposited on GO sheets (see Scheme 1 in the original paper, Gao et al., 2013). The obtained composites show higher photocatalytic degradation and disinfection activities than CdS under visible light irradiation.

However, using the mechanical mixing method, the interaction force between semiconductors and carbon materials is a little weak without the formation of chemical bonds, resulting in a relatively lower activity enhancement compared to that from hydrothermal/solvothemal methods. For example, Hong and his coworkers reported that $\mathrm{CdS} / \mathrm{GO}$ photocatalysts synthesized by in situ solvothermal method showed much higher $\mathrm{H}_{2}$ evolution activity than that synthesized by mechanical loading (Hong et al., 2015).

\section{Sol-Gel Method}

The sol-gel method is another widely applied method to get a close chemical interaction between semiconductors and carbon cocatalysts (Zarezade et al., 2011; Morales-Torres et al., 2012; $\mathrm{Ng}$ et al., 2012). Generally, this method need to prepare the sol 
first, which is then mixed with the carbon materials uniformly. Subsequently, the gel is formed by aging followed with high temperature calcination to obtain the final composites. This method can control the crystal structure and uniformity of the supported nanoparticles, thus can fabricate photocatalysts with high activities. Li et al. used surfactant wrapping sol-gel method for the synthesis of $\mathrm{CNT} / \mathrm{TiO}_{2}$ core-shell nanocomposites ( $\mathrm{Li}$ Z. et al., 2011). Using this method, they prepared uniform and distinct nanoscale anatase $\mathrm{TiO}_{2}$ layer on the CNTs with tailored $\mathrm{TiO}_{2}$ layer thickness with different Ti precursors (TEOTi, TTIP, and TBT). The $\mathrm{CNT} / \mathrm{TiO}_{2}$ composite prepared from TBT has thinner $\mathrm{TiO}_{2}$ layer that provides shorter traveling distance for electron transferring to the CNT core, the activity for the degradation of $\mathrm{MB}$ was therefore higher than those prepared from TEOTi and TTIP. Kim et al. prepared GO-TiO 2 nanofibers (NFs) by using a sol-gel method and an electrospinning technique (Kim et al., 2014). They also compared the activity of $\mathrm{GO}-\mathrm{TiO}_{2} \mathrm{NF}$ with $\mathrm{GO}(\mathrm{s})-\mathrm{TiO}_{2} \mathrm{NF}$ (prepared by covering GO sheets on external surface of $\mathrm{TiO}_{2} \mathrm{NF}$ ). Due to the stronger electronic coupling between $\mathrm{GO}$ and $\mathrm{TiO}_{2}$ matrix and the reduced light shielding effect by hiding GO inside of $\mathrm{TiO}_{2}$ $\mathrm{NF}$, the photocatalytic $\mathrm{H}_{2}$ production of $\mathrm{GO}-\mathrm{TiO}_{2} \mathrm{NF}$ was higher than $\mathrm{GO}(\mathrm{s})-\mathrm{TiO}_{2} \mathrm{NF}$.

Although the materials prepared by sol-gel method have high purity and uniform particle size, some problems still exist, such as relatively long reaction time, large shrinkage during drying, and easy sintering with high temperature calcination. For example, Ren et al. prepared nanostructured $\mathrm{LaFeO}_{3}$ nanoparticles (NPs) with $\mathrm{rGO}$ as a $2 \mathrm{D}$ template using a high temperature sol-gel method (Ren et al., 2016). Although the addition of C-support or rGO reduces the sintering degree of $\mathrm{LaFeO}_{3}$, it remains difficult to avoid sintering during the high temperature calcination for a long time.

\section{Other Methods}

Microwave-assisted method is a green synthesis method based on the characteristics of microwave heating with tremendous advantages (Tian et al., 2016). Preparation of catalysts with special structure and high yield would be finished in a very short time using microwave heating. Thangavel et al. prepared the ZnS-rGO nanohybrids via microwave irradiation for $20 \mathrm{~s}$ over two cycles (Thangavel et al., 2016). Interestingly, Raman spectrum of the hybrids indicates the complete reduction of GO into $\mathrm{rGO}$ via the microwave treatment. After $2 \mathrm{~h}$ of irradiation, the ZnS-rGO showed higher degradation efficiency for $\mathrm{MB}$ (about 55.23\%) and $\mathrm{RhB}$ (about 90.37\%) than that of bare ZnS (about $40.79 \%$ for $\mathrm{MB}$ and $56.56 \%$ for RhB), respectively. They attributed the high activity to tight intermolecular binding, good interfacial contact between $\mathrm{ZnS}$ and rGO in the hybrid, and enhanced charge-transfer properties of rGO in nanohybrid. Zhang et al. successfully synthesized the graphene/ $\mathrm{Cu}_{2} \mathrm{O}$ composites by a CVD (chemical vapor deposition) method. They also investigated the effects of the CVD growth parameters on the graphene flakes. The obtained composites were effective for the photocatalytic methyl orange degradation (Zhang et al., 2016a).

\section{PHOTOCATALYTIC APPLICATIONS}

The photocatalytic activity of pure semiconductors can be enhanced by the addition of carbon materials as cocatalysts. The obtained composites are mainly used for the photocatalytic pollutants degradation, water splitting, $\mathrm{CO}_{2}$ reduction, organic synthesis and so on (Abou Asi et al., 2013; Zhang et al., 2013a; Colmenares et al., 2016; Li K. et al., 2016; Zeng et al., 2017). In the following sections, we will focus their applications for photocatalytic hydrogen evolution and pollutants degradation.

\section{Photocatalytic Hydrogen Evolution}

Hydrogen is considered as one of the most potential alternative energy in the twenty-first century (Zhang et al., 2015b; Zou and Zhang, 2015). Among the present hydrogen production methods, photocatalytic water splitting driven by sustainable solar energy is an ideal way to achieve clean hydrogen production (Matsuoka et al., 2007; Wang et al., 2009; Hisatomi et al., 2014). Figure 2 describes the photocatalytic water splitting process with the presence of cocatalysts. Under the light irradiation, the electrons are photoexcited from the valence band (VB) to the conduction band $(\mathrm{CB})$, while the holes are left in the $\mathrm{VB}$, resulting in the separation of electrons and holes. Generally, for photocatalytic water splitting, the $\mathrm{CB}$ potential of semiconductor has to be more negative than hydrogen electrode potential $\mathrm{EH}^{+} / \mathrm{H}_{2}$, while the VB potential should be more positive than oxygen electrode potential $\mathrm{EO}_{2} / \mathrm{H}_{2} \mathrm{O}$ ( $\mathrm{Xu}$ et al., 2016). Moreover, due to the impact of semiconductor band bending and presence of surface overpotential, the band gap of semiconductor should be larger than $1.23 \mathrm{eV}$ to split water into $\mathrm{H}_{2}$ and $\mathrm{O}_{2}$ (Matsuoka et al., 2007; Moniz et al., 2015).

Carbon materials are effective $\mathrm{H}_{2}$ evolution cocatalysts for the semiconductors mainly due to their large surface area and good charge mobility on their surface. Martha et al. synthesized $\mathrm{RGO/InGaZn} \mathrm{nanocomposites} \mathrm{using} \mathrm{a} \mathrm{one-pot} \mathrm{hydrothermal}$ method (Martha et al., 2014). They also evaluated the effects of

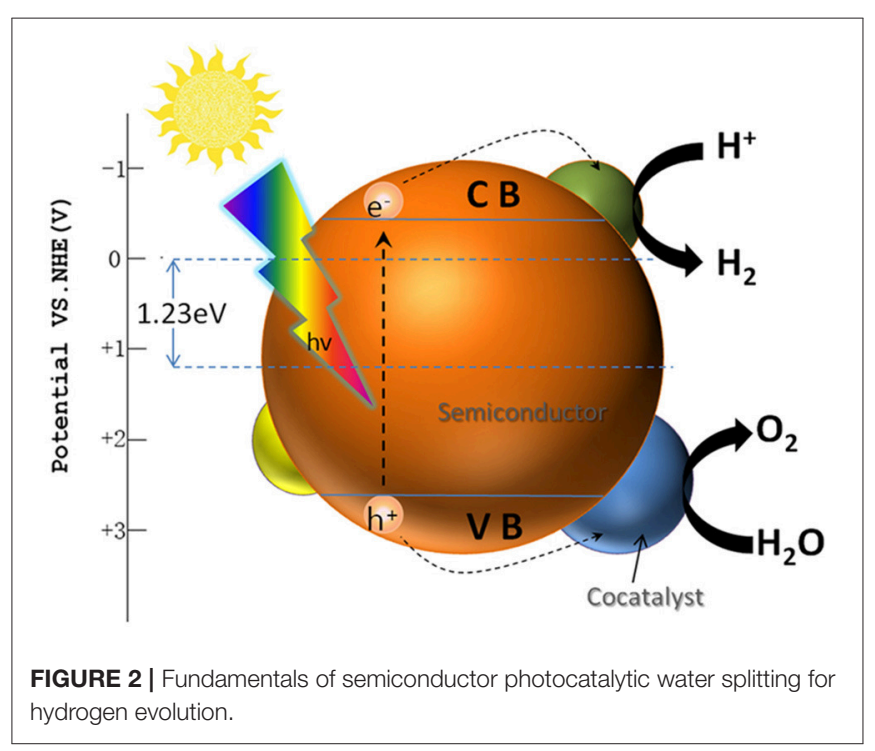



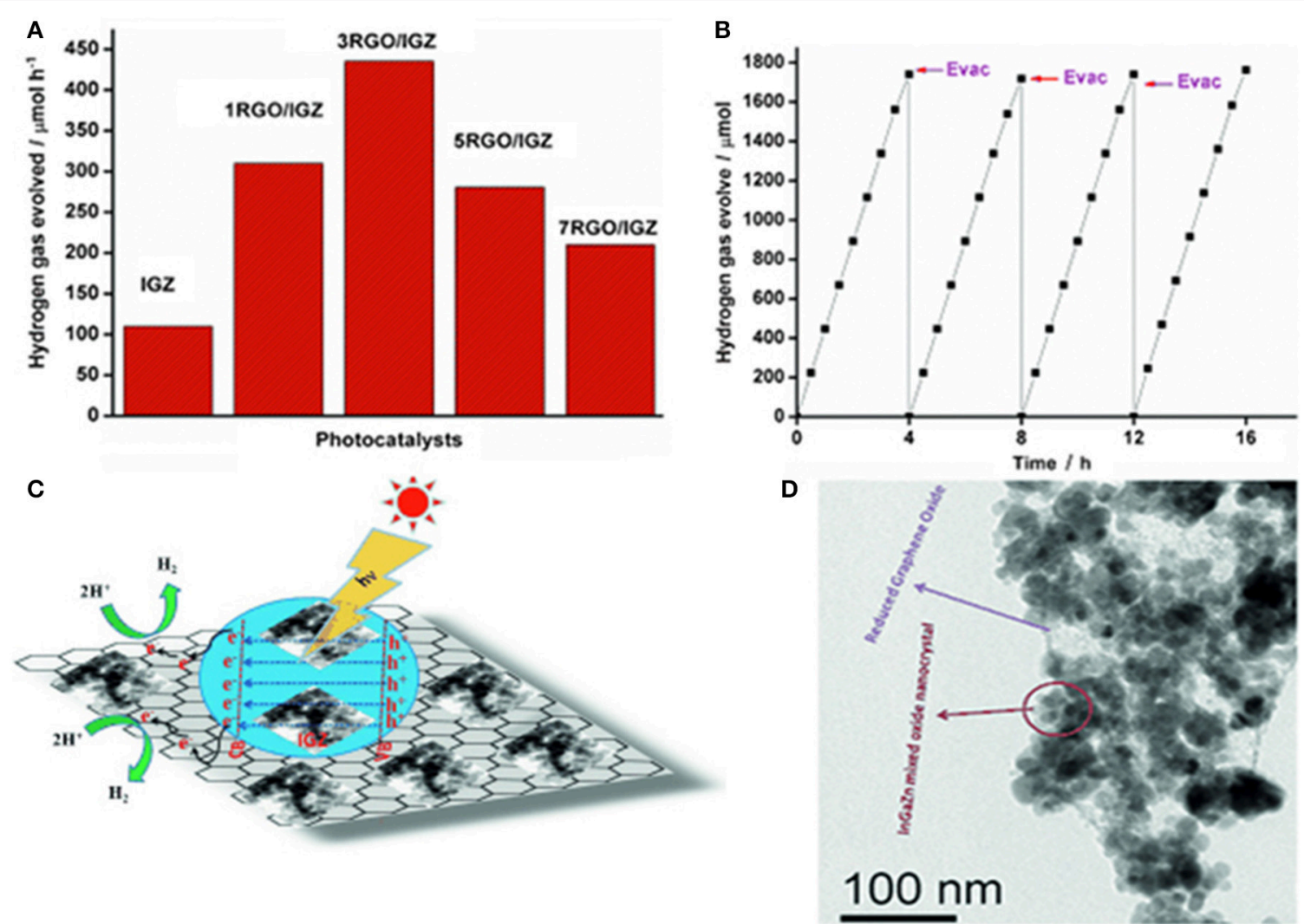

FIGURE 3 | (A) Photocatalytic $\mathrm{H}_{2}$ evolution over IGZ, 1RGO/IGZ, 3RGO/IGZ, 5RGO/IGZ, and 7RGO/IGZ under visible-light irradiation; (B) Time course of H2 evolution over 3RGO/IGZ; (C) Mechanism of photocatalytic $\mathrm{H}_{2}$ composites; (D) TEM image of 3RGO/IGZ (Reprinted from Martha et al., 2014, Copyright 2014, with permission from Wiley-VCH).

RGO percentage on the $\mathrm{H}_{2}$ evolution activity under visible-light irradiation $(\lambda>400 \mathrm{~nm}$ ) (Figure 3). Three wt $\% \mathrm{rGO}$ was proved to be the best loading percentage, and the $\mathrm{H}_{2}$ generation rate can be as high as $435 \mu \mathrm{mol} / \mathrm{h}$ (Figure 3A). As shown in Figure 3D, InGaZn was uniformly dispersed on the surface of RGO, which was beneficial for the electrons moving from InGaZn to RGO. Moreover, the RGO could also provide more active adsorption sites and photocatalytic reaction centers. The stability test of RGO/InGaZn composite was also tested, and no deactivation could be found after four recycles (Figure 3B).

Silva et al. combined $\mathrm{TiO}_{2}$ and CNTs using two different methods: hydration-dehydration labeled as $\left(\mathrm{CNT}_{\mathrm{ox}}-\mathrm{TiO}_{2}\right)$ and one-pot oxidation (labeled as $\left.\left(\mathrm{CNT}-\mathrm{TiO}_{2}\right)_{\text {ox }}\right)$ (Silva et al., 2015). One wt $\% \mathrm{Pt}$ was then loaded followed by calcination at $473 \mathrm{~K}$ and $673 \mathrm{~K}$, respectively. The optimized catalyst $\mathrm{Pt} /\left(\mathrm{CNT}-\mathrm{TiO}_{2}\right)_{\mathrm{ox}^{-}}$ 473 could obtain a $\mathrm{H}_{2}$ evolution rate of $485 \mu \mathrm{mol} / \mathrm{h}, 2.4$ times compared to the $\mathrm{Pt} / \mathrm{TiO}_{2}-473$. According to the infrared attenuated total reflectance (ATR) spectra (see Figure 1 in the original paper, Silva et al., 2015), the bands from C = C and C$\mathrm{H}$ are weaker in $\left(\mathrm{CNT}-\mathrm{TiO}_{2}\right)_{\mathrm{ox}}$ than in $\mathrm{CNT}_{\mathrm{ox}}-\mathrm{TiO}_{2}$, indicating a better dispersion of the $\mathrm{TiO}_{2}$ particles at the surface of CNT in $\left(\mathrm{CNT}-\mathrm{TiO}_{2}\right)_{\mathrm{ox}}$. This conclusion can be further confirmed by SEM and TEM images in. The better photocatalysis performance of $\left(\mathrm{CNT}-\mathrm{TiO}_{2}\right)_{\mathrm{ox}}$ might be related to the stronger interface interaction between $\mathrm{TiO}_{2}$ and CNT, which is promoted by the oxidative treatment according to the ATR analysis.

Loading carbon materials as cocatayst, the bandgap of semiconductors could be narrowed to utilize the visible light with longer wavelength. $\mathrm{Yu}$ et al. prepared the CQDs/P25 composites with a "dyade"-like structure and applied them for photocatalytic hydrogen evolution under both UV-vis and visible light irradiation (Figure 4) (Yu H. et al., 2014). With methanol as the sacrificial agent, CQDs/P25-1.5 wt\% showed the best photocatalytic performance under UV-vis light irradiation, and the evolution rate could reach $9.1 \mu \mathrm{mol} / \mathrm{h}, 4$ times higher than that of pure P25 $(2.3 \mu \mathrm{mol} / \mathrm{h})$. While CQDs/P25-2.0 wt\% was the optimized one under visible light with a $\mathrm{H}_{2}$ evolution rate of $0.5 \mu \mathrm{mol} / \mathrm{h}$. The photocurrent response of these composites are shown in Figures $\mathbf{4 A , B}$, which are consistent with the photocatalytic results. They believed that CQDs played dual roles to improve the photocatalytic activity of P25. CQDs could act as electron acceptors to improve the charge separation under UV-vis light irradiation. Meanwhile, they also served as a photosensitizer to sensitize P25 into a visible light response "dyade" structure for $\mathrm{H}_{2}$ evolution under visible light irradiation.

Heteroatom doped carbon materials, such as nitrogen doped graphene, are proved to be better cocatalysts for semiconductor photocatalysts in recent years (Putri et al., 

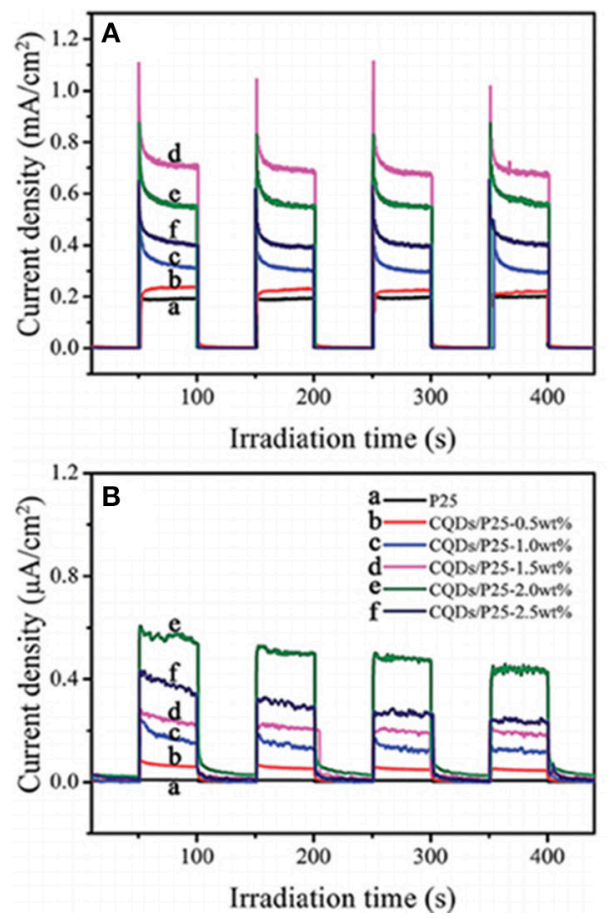

C
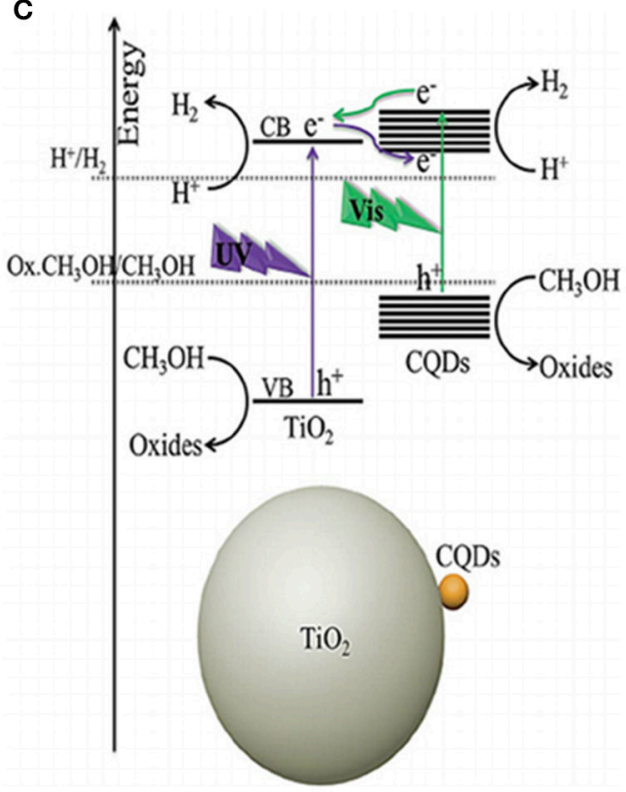

FIGURE 4 | (A) Schematic illustration for the photocatalytic $\mathrm{H}_{2}$ production mechanism over the CQDs/P25 under UV-Vis and visible light ( $\lambda$ > 450 nm) irradiation; (B,C) The transient photocurrent response of P25 and the CQDs/P25 composites with different amount of CQDs in 1 M Na $2 \mathrm{SO}_{4}$ aqueous solution under $\mathrm{UV}$-Vis light and visible light $(\lambda>450 \mathrm{~nm}$ ) irradiation (Reprinted from Yu H. et al., 2014, Copyright 2014, with permission from Royal Society of Chemistry).

2015). Yue et al. synthesized a ternary visible-light-driven photocatalyst for hydrogen evolution reaction. After decorating the $\mathrm{CdS} / \mathrm{Nb}_{2} \mathrm{O}_{5}$ heterojunction structure with $\mathrm{N}$-doped graphene (NGR) nanosheets (Yue et al., 2017), the hybrid photocatalyst ( $2 \mathrm{wt} \% \mathrm{NGR}$ ) exhibited a high $\mathrm{H}_{2}$ evolution rate of $100 \mu \mathrm{mol}$ $\mathrm{h}^{-1} \mathrm{~g}^{-1}$, which was about 7.7 times than the pure CdS. Doping with nitrogen atom could change the electron density of the GR surface, thus can separation the photogenerated charges more efficiently. Jia et al. synthesized a series of nanocomposites by coupling CdS nanoparticles with NGR through calculation (Jia et al., 2011). The N-graphene/CdS was proved to be more efficient photocatalysts for hydrogen evolution compared to the CdS supported on undoped graphene. Significantly, the photocatalytic $\mathrm{H}_{2}$ evolution rate of the $\mathrm{N}$-graphene (2 wt \%)/CdS reached $210 \mu \mathrm{mol} \mathrm{h}^{-1}$ without the addition of metal cocatalyst, which was much higher than graphene/CdS $\left(99 \mu \mathrm{mol} \mathrm{h}^{-1}\right)$ and $\mathrm{GO} / \mathrm{CdS}\left(95 \mu \mathrm{mol} \mathrm{h}^{-1}\right)$ with the same percentage of cocatalysts.

\section{Photocatalytic Degradation of Pollutants}

Photocatalytic degradation of pollutants is another important application of photocatalysts. Photocatalysts can adsorb and degrade pollutants in water and toxic gas in air under illustration, which thus has great potential for environmental remediation. Previous studies have shown that photocatalysis technology can not only degrade organic pollutants into $\mathrm{CO}_{2}, \mathrm{H}_{2} \mathrm{O}$, and inorganic salt, but also eliminate the heavy metal ions (Akpan and Hameed, 2009; Peng et al., 2014; Murgolo et al., 2015; Jing et al., 2017).
Ming et al. synthesized dandelion-like ZnS/CQDs hybrid materials using hydrothermal method with CTAB as surfactant (Ming et al., 2016). As shown in Figures 5A-D, some dark dots are distributed on the $\mathrm{ZnS}$ nanowires uniformly. Coating the optimal content of $2 \mathrm{wt} \%$ CQDs, the photocatalyst showed the highest degradation rate, which was about 1.67 and 2.11 times higher than bare $\mathrm{ZnS}$ for $\mathrm{MB}$ and $\mathrm{RhB}$, respectively. As illustrated in Figure 5E, the intensity of the PL emission band decreased obviously after the loading of CQDs on ZnS. The $2 \mathrm{wt} \% \mathrm{CQDs} / \mathrm{ZnS}$ possessed the lowest intensity, suggesting the lowest recombination possibility of photoexcited holes and electrons. They also proposed the photocatalytic mechanisms on the CQDs/ZnS hybrid:

$$
\begin{aligned}
& \mathrm{ZnS}+\mathrm{hv} \rightarrow \mathrm{e}_{\mathrm{ZnS}}{ }^{-}+\mathrm{h}_{\mathrm{ZnS}}{ }^{+} \\
& \mathrm{e}_{\mathrm{ZnS}}^{-} \rightarrow \mathrm{e}_{\mathrm{CQDs}}^{-} \\
& \mathrm{e}_{\mathrm{CQDs}}^{-}+\mathrm{O}_{2} \rightarrow{ }^{*} \mathrm{O}_{2}^{-} \\
& \mathrm{h}_{\mathrm{ZnS}}^{+}+\mathrm{H}_{2} \mathrm{O} \rightarrow{ }^{*} \mathrm{OH}^{-} \\
& 2^{*} \mathrm{OH} \rightarrow \mathrm{H}_{2} \mathrm{O}_{2} \\
& \mathrm{H}_{2} \mathrm{O}_{2}+{ }^{*} \mathrm{O}_{2}^{-} \rightarrow \mathrm{OH}^{-}+{ }^{*} \mathrm{OH}+\mathrm{O}_{2} \\
& { }^{*} \mathrm{OH}+\text { dye } \rightarrow \mathrm{H}_{2} \mathrm{O}+\mathrm{CO}_{2}+\text { intermediates }
\end{aligned}
$$

Qi and his co-workers prepared a series of fullerene-modified anatase $\mathrm{TiO}_{2}\left(\mathrm{C}_{60} @ \mathrm{a}-\mathrm{TiO}_{2}\right)$ nanocomposites by a simple solution phase method (Qi et al., 2016). By the introduction of $\mathrm{C}_{60}$, the activity of $\mathrm{C}_{60} @ \mathrm{a}-\mathrm{TiO}_{2}$ for photocatalytic degradation of $\mathrm{MB}$ 

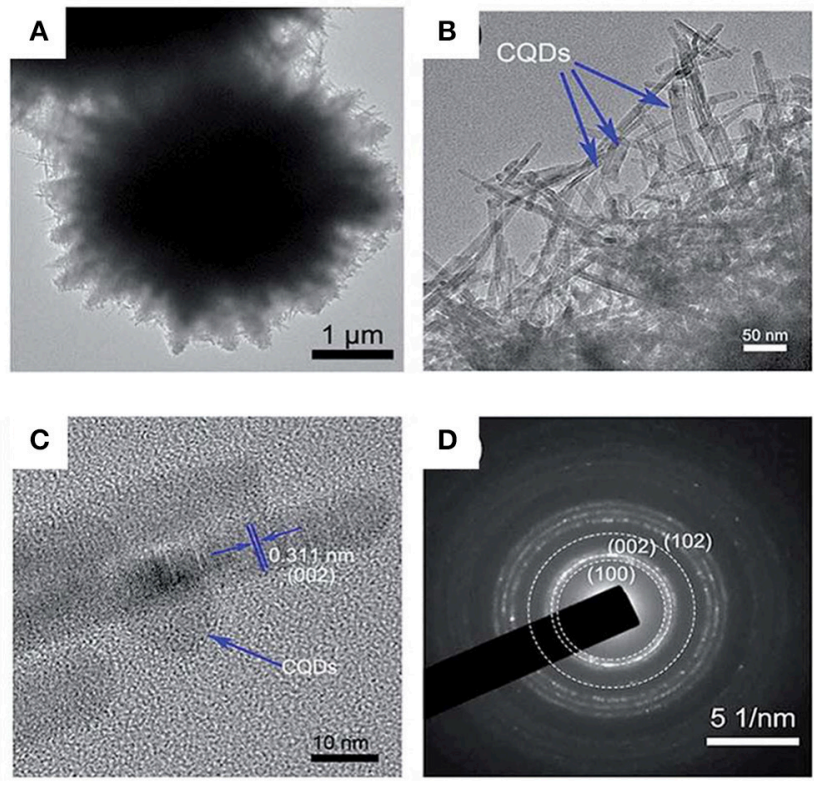

FIGURE 5 | (A,B) TEM images of CQDs/ZnS hybrid materials; (C) HRTEM image of the CQDs/ZnS hybrid materials; (D) SAED of the dandelion-like ZnS; (E) PL spectra of pure ZnS and CQDs/ZnS hybrid materials (Reprinted from Ming et al., 2016, Copyright 2016, with permission from Royal Society of Chemistry).

could be enhanced greatly under UV-A light irradiation. In order to confirm the electronic structures of $\mathrm{C}_{60} @ \mathrm{a}-\mathrm{TiO}_{2}$, the density functional theory (DFT) was used for a theoretical calculation toward the $\mathrm{C}_{60}-\mathrm{COOH} @ \mathrm{a}-\mathrm{TiO}_{2}$ (101) surface. The adsorption energy and the projected density of states (PDOS) for the $\mathrm{C}_{60^{-}}$$\mathrm{COOH} @ \mathrm{a}-\mathrm{TiO}_{2}$ (101) surface were calculated. Strong covalent interaction between $\mathrm{C}_{60}$ and the $\mathrm{a}-\mathrm{TiO}_{2}(101)$ surface was present with the calculated adsorption energy of $3.61 \mathrm{eV}$. Moreover, the introduction of $\mathrm{C}_{60}$ narrows the band gap to $0.8 \mathrm{eV}$, resulting in the red shift of light absorption edge of the $\mathrm{C}_{60}$-COOH@a$\mathrm{TiO}_{2}$ heterojunctions. According to the DFT results, there is an additional doping state present between the valance band and conduction band by the incorporation of $\mathrm{C}_{60}$ on the $\mathrm{a}-\mathrm{TiO}_{2}(101)$ surface. The activity of $\mathrm{C}_{60} @ \mathrm{a}-\mathrm{TiO}_{2}$ is therefore enhanced with more efficient charge separation efficiency and increased light absorption range.

Sampaio et al. used both $\mathrm{GO}-\mathrm{TiO}_{2}$ and $\mathrm{CNT}-\mathrm{TiO}_{2}$ materials for the photocatalytic degradation of the cyanobacterial toxin, microcystin-LA (MC-LA) under simulated solar light and visible light irradiation (Sampaio et al., 2015). The GO-TiO 2 composite containing $4 \mathrm{wt} \%$ of $\mathrm{GO}$ exhibited the highest photocatalytic activity under both simulated solar light and visible light irradiation. The enhanced activity of $\mathrm{GO}-\mathrm{TiO}_{2}$ was attributed to the optimal assembly and interfacial coupling between $\mathrm{TiO}_{2}$ nanoparticles and GO sheets, which can effectively inhibit electron-hole recombination. While the activity of CNT$\mathrm{TiO}_{2}$ for the MC-LA removal under visible light irradiation was mostly due to adsorption instead of photocatalytic degradation.

Murgolo et al. fabricated a composite photocatalyst by combining SWCNTs with nano-sized $\mathrm{TiO}_{2}$ NRs (Murgolo et al., 2015). The composite showed tailored photocatalytic properties for the photocatalytic degradation of a mixture of 22 organic pollutants under both UV and simulated solar light. The experiment results showed that this composite displayed comparable degradation rates over Degussa P25 under UV irradiation. While the $\mathrm{SWCNTs} / \mathrm{TiO}_{2}$ showed slightly lower efficiency than Degussa P25 under simulated solar irradiation. The SWCNTs $/ \mathrm{TiO}_{2}$ can be reused easily by a mild centrifugation or a filtration. This photocatalyst has proved to be a promising candidate in photocatalytic pollutants degradation, which can also be integrated with a biological step for the enhanced removal of emerging organic pollutants.

Heteroatoms doped carbon materials are also effective cocatalysts for photocatalytic degradation reaction. Liu et al. synthesized $\mathrm{N}-\mathrm{CNT} / \mathrm{mpg}-\mathrm{C}_{3} \mathrm{~N}_{4}$ composites via thermal polycondensation (Liu J. et al., 2017). N-CNT has better electronic conductivity and more defective structure than undoped CNT, which could therefore accept electrons more easily. Benefiting from the synergistic effect between N-CNT and mpg- $\mathrm{C}_{3} \mathrm{~N}_{4}$, the composites show enhanced photo-degradation activity for rhodamine $\mathrm{B}$, methyl orange and tetracycline hydrochloride under visible light irradiation. Due to the special 2D structure of graphene, which can also be combined with other layered materials to fabricate hybrid cocatalysts (Chen et al., 2017; Peng et al., 2017). Our group have used the $\mathrm{MoS}_{2}$ /graphene hybrids for the modification of CdS and $\mathrm{Ag}_{3} \mathrm{PO}_{4}$, and the obtained composites showed improved photocatalytic activity for phenols degradation and nitroaromatic compounds detoxification (Peng et al., 2014, 2016). The photo-activity of the final composite could also be adjusted by changing the ratio of $\mathrm{MoS}_{2}$ and graphene. 


\section{COMPARISON OF CARBON ALLOTROPES AS COCATALYSTS}

There have been some other relevant reviews on this subject, but as far as we are concerned, a horizontal comparison of these carbon cocatalysts in photocatalysis field is still lack. In this section, we summarized some examples which compared different carbon cocatalysts for the modification of semiconductors. Zarezade et al. used sol-gel method to synthesize $\mathrm{TiO}_{2} / \mathrm{AC}$ and $\mathrm{TiO}_{2} / \mathrm{MWCNT}$ hybrid materials (Zarezade et al., 2011). Although the surface area of $\mathrm{TiO}_{2}$ /MWCNTs was smaller than that of $\mathrm{TiO}_{2} / \mathrm{ACs}$, the activity of $\mathrm{TiO}_{2} / \mathrm{MWCNTs}$ was even higher for photocatalytic degradation of AB92. The defects of MWCNTs could be used as anchor sites for the growth of $\mathrm{TiO}_{2}$ crystallites, which can lead to the uniform distribution of $\mathrm{TiO}_{2}$ on the MWCNT surface. After calcination of the composite at $500^{\circ} \mathrm{C}$ (Figure 6A), a remarkable photocatalytic performance could be achieved with a maximum degradation percentage of $86 \%$ in $2 \mathrm{~h}$ (Figure 6B).

Ye's group compared the photocatalytic behaviors of CdSgraphene (CdS-GR) and CdS-carbon nanotube (CdS-CNT) nanocomposites as photocatalysts for the hydrogen evolution and the degradation of methyl orange (MO) under visiblelight irradiation (Ye et al., 2012). Figure 7A reveals that both the CdS-GR and the CdS-CNT composites display enhanced photocatalytic $\mathrm{H}_{2}$ evolution activities. Furthermore, the CdS-GR composite is more efficient than the CdSCNT composite under their optimized mass ratios. The $\mathrm{H}_{2}$ evolution rate over the CdS-GR composite could reach $70 \mu \mathrm{mol}$ $\mathrm{h}^{-1}$, which is 1.3 times higher than that of the CdS-CNT $\left(52 \mu \mathrm{mol} \mathrm{h}{ }^{-1}\right)$. Similarly, Figure $7 \mathbf{B}$ shows that GR is more efficient to enhance the photocatalytic performance of CdS for the degradation of MO. The degradation percentage of MO over the optimized CdS-GR (1: 0.01) is as large as $95 \%, 1.8$ times higher than that of the optimized CdS-CNT (1: 0.03 ) after $60 \mathrm{~min}$ irradiation (Figure 7C). The stronger interaction and larger contact interface between CdS and GR facilitate the transfer of photogenerated electrons from CdS to GR, leading to a higher efficiency in the separation of photogenerated electron-hole pairs and a higher photocatalytic performance of the CdS-GR composite than the CdS-CNT composite.

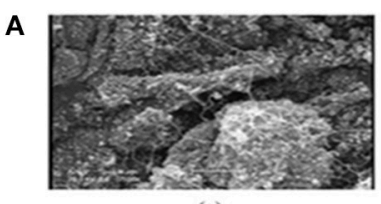

(a)

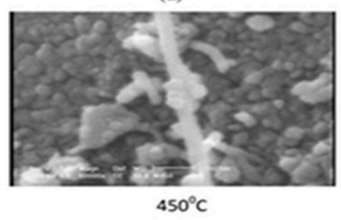

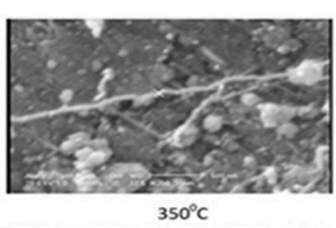

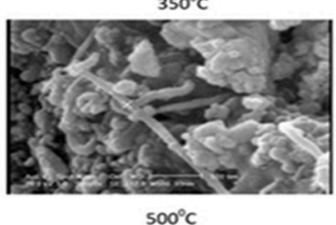

B

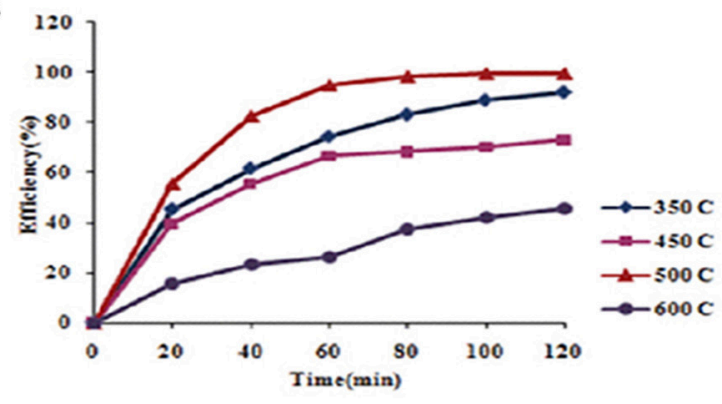

FIGURE 6 | (A) SEM images of the (A) acid treated MWCNTs (1 mm), and $\mathrm{TiO}_{2} / \mathrm{MWCNTs}$ calcined at various temperatures; (B) Effect of calcination temperatures on photocatalytic activity of $\mathrm{TiO}_{2}$ /MWCNTs (Reprinted from Zarezade et al., 2011, Copyright 2011, with permission from Royal Society of Chemistry).
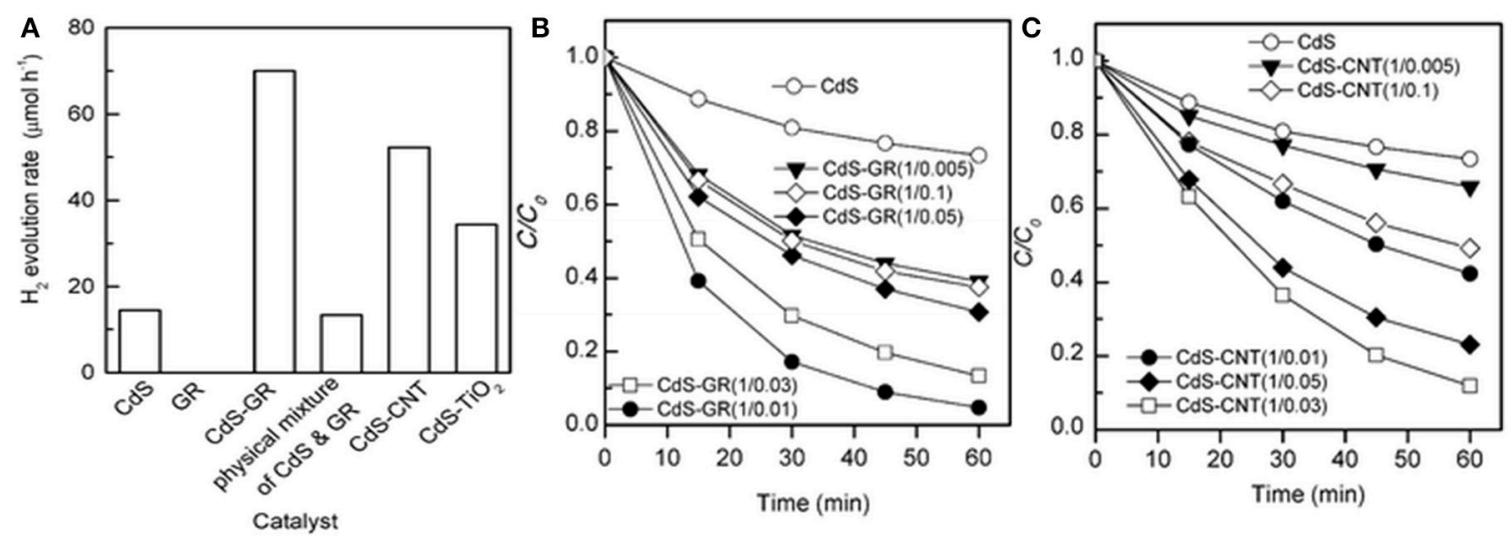

FIGURE 7 | (A) Comparison of photocatalytic $\mathrm{H}_{2}$ evolution rate of different photocatalysts; (B) Photocatalytic degradation of MO over the CdS-GR and (C) CdS-CNT composites with different mass ratios of CdS: carbon material under visible-light irradiation (Reprinted from Ye et al., 2012, Copyright 2012, with permission from Royal Society of Chemistry). 
Cherevan and coworkers hybridized both multi-walled CNTs and graphene oxide (GO) with $\mathrm{Ta}_{2} \mathrm{O}_{5}$ semiconductor via a in situ hydrothermally assisted sol-gel method (Cherevan et al., 2014). Surprisingly, $\mathrm{CNT}-\mathrm{Ta}_{2} \mathrm{O}_{5}$ hybrid exhibited superior performance over $\mathrm{GO}-\mathrm{Ta}_{2} \mathrm{O}_{5}$ hybrid, and a maximum $\mathrm{H}_{2}$ evolution rate of $1,600 \mu \mathrm{mol} \mathrm{h}^{-1}$ could be obtained for CNT$\mathrm{Ta}_{2} \mathrm{O}_{5}$. This result is opposite to many other studies, which could be attributed to two reasons: (1) the amount of $\mathrm{Ta}_{2} \mathrm{O}_{5}$ in the GO hybrid is much lower than in the CNT hybrid; (2) annealed CNTs are expected to possess better charge transfer properties than highly defective GO.

Jing et al. compared the degradation efficiencies of methylene blue (MB) over AgSiOx@CNT and AgSiOx@RGO nanocomposites under visible light (Jing et al., 2017). Interestingly, AgSiOx@CNT has a better photodegradation performance than AgSiOx@RGO at a small amount of CNTs, while the removal rate with AgSiOx@RGO is faster than AgSiOx@CNT at high carbon contents. This is probably because the different functional mechanism of these two carbon materials. The low content of CNT could boost the synergistic effect of the nanocomposite by reducing the electron transfer resistances and prolonging the lifetime of electron-hole pairs. However, as for AgSiOx@RGO, adsorption effect is dominant rather than photodegradation as RGO contains residual oxygen-containing groups.

Yang et al. presented a comparative study of photocatalytic selective oxidation on several carbon based photocatalysts (Yang M. Q. et al., 2013). They synthesized a series of $\mathrm{TiO}_{2}-\mathrm{GR},-\mathrm{CNT}$, and $-\mathrm{C}_{60}$ photocatalysts by combining sol-gel with hydrothermal methods. These three different carbon allotropes affected slightly in the morphology, crystal phase, particle size, pore volume and surface area the of the supported $\mathrm{TiO}_{2}$ nanocrystals. The $\mathrm{TiO}_{2}$-carbon (GR, CNT, and $\mathrm{C}_{60}$ ) have similar photocatalytic activities and analogous reaction mechanisms toward selective oxidation of benzyl alcohol. Different preparation methods could obtain different structural composition and synergetic interaction between $\mathrm{TiO}_{2}$ and carbon, which therefore have a greater impact on the photocatalytic performance of $\mathrm{TiO}_{2}$ carbon composites. The comparison shows that GR fails to prove its unique advantage compared to the other two carbon allotropes. Similarly, Zhang et al. investigated $\mathrm{TiO}_{2}$-Graphene as high-performance photocatalyst for the gas-phase degradation of benzene (Zhang et al., 2010). They concluded that GR was in essence the same as other carbon materials (carbon nanotube, activated carbon, and fullerene) as cocatalysts on enhancement of photocatalytic activity of $\mathrm{TiO}_{2}$, although GR has unique structural and electronic properties in comparison with other carbon allotropes.

Due to the special 2D structure and excellent physical/chemical properties, we expected the graphene will show better performance compared to other carbon allotropes (An and Yu, 2011; Zhang et al., 2011). However, it didn't show superior cocatalytic properties compared to the CNT or carbon quantum for the modification of some semiconductors (Ma et al., 2016). Researchers has tried to modify the graphene further by heteroatoms doping or activation method, which could increase its electric conductivity or surface area. The performance of the modified graphene could be then enhanced further as photocatalytic cocatalysts, thus increasing its real application potential.

\section{MECHANISM OF CARBON COCATALYSTS FOR PHOTOCATALYTIC ACTIVITY IMPROVEMENT}

It has been proposed that the photocatalytic activity enhancement is due to the synergistic effect between semiconductor and carbon materials. Generally, carbon materials play four primary roles as cocatalysts for the activity enhancement of the semiconductors (Tan et al., 2012; Bai et al., 2016). (1) They provide a structure with larger specific surface area over which the active component can be well-dispersed, thus increasing the active sites. Activated carbon is amorphous carbon with a specific surface up to $3,000 \mathrm{~m}^{2} \mathrm{~g}^{-1}$ (Strobel et al., 2006). Graphene, the 2-dimensional nanosheets composed of $\mathrm{sp}^{2}$-hybridized carbon atoms, possesses an extremely high specific surface area (theory value of $2,630 \mathrm{~m}^{2} \mathrm{~g}^{-1}$ ) (Fan X. et al., 2015). While the CQDs can distribute uniformly on the surface of semiconductor materials because of its small size. (2) During the photocatalytic degradation of organic pollutants, carbon materials can be used as adsorbent to improve the adsorption capacity of semiconductors (Matos et al., 2001; Ai et al., 2015). (3) Carbon materials can be doped as a photosensitizer for bandgap narrowing, which is favorable for expanding the visible light absorption region of semiconductors. (4) By the formation of carbon materials-semiconductor heterojunction, the excellent electron transfer could be achieved, leading to the enhanced charge separation efficiency and photocatalytic activity (Guldi et al., 2006; Li X. et al., 2016; Shi et al., 2017).

\section{CONCLUSIONS AND FUTURE PROSPECTS}

Carbon materials are important photocatalytic cocatalysts due to their low cost and high efficient. In this review, we summarized the recent development of the carbon materials based semiconductor photocatalysts, including their synthesis methods and the applications for $\mathrm{H}_{2}$ evolution and pollutants degradation. Zero-dimensional $\mathrm{C}_{60}$, CQDs, one-dimensional CNTs, two-dimensional GR, and activated carbon are all involved to provide valuable information for metal free cocatalysts selection. Although much progress has been achieved, some essential issues are still unaddressed, especially for the activity and stability enhancement mechanisms. Studies about the interface between the semiconductors and the cocatalysts should be helpful for new carbon materials based photocatalysts development. Computational chemistry using DFT could also provide valuable information for the photocatalysts design. Although more in-depth studies are still needed, carbon materials based photocatalysts have great 
potential to address various environmental and energy-related problems.

\section{AUTHOR CONTRIBUTIONS}

$\mathrm{WH}$ chose the references and edit the draft. ZL provided assistance for literature search and some revision. YL, XF, FZ, and GZ provided professional advice. WP designed the main content

\section{REFERENCES}

Abou Asi, M., Zhu, L., He, C., Sharma, V. K., Shu, D., Li, S., et al. (2013). Visible-light-harvesting reduction of $\mathrm{CO}_{2}$ to chemical fuels with plasmonic Ag@AgBr/CNT nanocomposites. Catal. Today 216, 268-275. doi: 10.1016/j.cattod.2013.05.021

Ai, B., Duan, X., Sun, H., Qiu, X., and Wang, S. (2015). Metal-free graphenecarbon nitride hybrids for photodegradation of organic pollutants in water. Catal. Today 258, 668-675. doi: 10.1016/j.cattod.2015.01.024

Akpan, U. G., and Hameed, B. H. (2009). Parameters affecting the photocatalytic degradation of dyes using $\mathrm{TiO}_{2}$-based photocatalysts: a review. J. Hazard. Mater. 170, 520-529. doi: 10.1016/j.jhazmat.2009.05.039

An, T., Chen, J., Nie, X., Li, G., Zhang, H., Liu, X., et al. (2012). Synthesis of carbon nanotube-anatase $\mathrm{TiO}_{2}$ sub-micrometer-sized sphere composite photocatalyst for synergistic degradation of gaseous styrene. ACS Appl. Mater. Interfaces 4, 5988-5996. doi: 10.1021/am3016476

An, X. Q., and Yu, J. C. (2011). Graphene-based photocatalytic composites. RSC Adv. 1, 1426-1434. doi: 10.1039/clra00382h

Bai, S., Wang, L., Chen, X., Du, J., and Xiong, Y. (2014). Chemically exfoliated metallic $\mathrm{MoS}_{2}$ nanosheets: a promising supporting co-catalyst for enhancing the photocatalytic performance of $\mathrm{TiO}_{2}$ nanocrystals. Nano Res. 8, 175-183. doi: 10.1007/s12274-014-0606-9

Bai, S., Yin, W., Wang, L., Li, Z., and Xiong, Y. (2016). Surface and interface design in cocatalysts for photocatalytic water splitting and $\mathrm{CO}_{2}$ reduction. RSC $\mathrm{Adv}$. 6, 57446-57463. doi: 10.1039/C6RA10539D

Bai, X., Sun, C., Liu, D., Luo, X., Li, D., Wang, J., et al. (2017). Photocatalytic degradation of deoxynivalenol using graphene/ $\mathrm{ZnO}$ hybrids in aqueous suspension. Appl. Catal. B 204, 11-20. doi: 10.1016/j.apcatb.2016.11.010

Cao, S. W., and Yu, J. G. (2016). Carbon-based $\mathrm{H}_{2}$-production photocatalytic materials. J. Photochem. Photobiol. C Photochem. Rev. 27, 72-99. doi: 10.1016/j.jphotochemrev.2016.04.002

Cao, S., and $\mathrm{Yu}, \mathrm{J}$. (2014). g- $\mathrm{C}_{3} \mathrm{~N}_{4}$-based photocatalysts for hydrogen generation. J. Phys. Chem. Lett. 5, 2101-2107. doi: 10.1021/jz500546b

Chen, C., Ma, W., and Zhao, J. (2010a). Semiconductor-mediated photodegradation of pollutants under visible-light irradiation. Chem. Soc. Rev. 39, 4206-4219. doi: 10.1039/b921692h

Chen, W., Fan, Z., Zhang, B., Ma, G., Takanabe, K., Zhang, X., et al. (2011). Enhanced visible-light activity of Titania via confinement inside carbon nanotubes. J. Am. Chem. Soc. 133, 14896-14899. doi: 10.1021/ja205997x

Chen, X. B., Shen, S. H., Guo, L. J., and Mao, S. S. (2010b). Semiconductorbased photocatalytic hydrogen generation. Chem. Rev. 110, 6503-6570. doi: $10.1021 /$ cr1001645

Chen, Y., Sun, H., and Peng, W. (2017). 2D Transition Metal dichalcogenides and graphene-based ternary composites for photocatalytic hydrogen evolution and pollutants degradation. Nanomaterials 7:e62. doi: 10.3390/nano7030062

Cherevan, A. S., Gebhardt, P., Shearer, C. J., Matsukawa, M., Domen, K., and Eder, D. (2014). Interface engineering in nanocarbon- $\mathrm{Ta}_{2} \mathrm{O}_{5}$ hybrid photocatalysts. Energy Environ. Sci. 7, 791-796. doi: 10.1039/C3EE42558D

Chowdhury, S., and Balasubramanian, R. (2014). Graphene/semiconductor nanocomposites (GSNs) for heterogeneous photocatalytic decolorization of wastewaters contaminated with synthetic dyes: a review. Appl. Catal. B Environ. 160, 307-324. doi: 10.1016/j.apcatb.2014.05.035

Colmenares, J. C., Varma, R. S., and Lisowski, P. (2016). Sustainable hybrid photocatalysts: titania immobilized on carbon materials derived and revised the manuscript. All authors read and approved the final manuscript version to be submitted.

\section{ACKNOWLEDGMENTS}

This research was supported by the project No. 21506158 from the National Natural Science Foundation of China (NSFC).

from renewable and biodegradable resources. Green Chem. 18, 5736-5750. doi: 10.1039/C6GC02477G

Devi, L. G., and ArunaKumari, M. L. (2014). Synergistic effect between orthorhombic $\alpha$-sulfur and $\mathrm{TiO}_{2}$ as co-photocatalysts for efficient degradation of methylene blue: a mechanistic approach. J. Mol. Catal. Chem. 391, 99-104. doi: 10.1016/j.molcata.2014.04.012

Di, J., Li, S. X., Zhao, Z. F., Huang, Y. C., Jia, Y., and Zheng, H. J. (2015). Biomimetic CNT@TiO 2 composite with enhanced photocatalytic properties. Chem. Eng. J. 281, 60-68. doi: 10.1016/j.cej.2015.06.067

Fan, X., Zhang, G., and Zhang, F. (2015). Multiple roles of graphene in heterogeneous catalysis. Chem. Soc. Rev. 44, 3023-3035. doi: 10.1039/C5CS00094G

Fan, Y., Ma, W., Han, D., Gan, S., Dong, X., and Niu, L. (2015). Convenient recycling of $3 \mathrm{D} \mathrm{AgX} / \mathrm{Graphene}$ aerogels $(\mathrm{X}=\mathrm{Br}, \mathrm{Cl})$ for efficient photocatalytic degradation of water pollutants. Adv. Mater. 27, 3767-3773. doi: 10.1002/adma.201500391

Fujishima, A., and Honda, K. (1972). Electrochemical photolysis of water at a semiconductor electrode. Nature 238, 37-38. doi: 10.1038/ $238037 \mathrm{a} 0$

Gao, P., Liu, J., Sun, D. D., and Ng, W. (2013). Graphene oxide-CdS composite with high photocatalytic degradation and disinfection activities under visible light irradiation. J. Hazard. Mater. 250-251, 412-420. doi: 10.1016/j.jhazmat.2013.02.003

Guldi, D. M., Rahman, A., Sgobba, V., and Ehli, C. (2006). Multifunctional molecular carbon materials-from fullerenes to carbon nanotubes. Chem. Soc. Rev. 35, 471-487. doi: 10.1039/b511541h

Guo, F., Shi, W., Guan, W., Huang, H., and Liu, Y. (2017). Carbon dots/g$\mathrm{C}_{3} \mathrm{~N}_{4} / \mathrm{ZnO}$ nanocomposite as efficient visible-light driven photocatalyst for tetracycline total degradation. Sep. Purification Technol. 173, 295-303. doi: 10.1016/j.seppur.2016.09.040

Han, C., Chen, Z., Zhang, N., Colmenares, J. C., and Xu, Y. J. (2015). Hierarchically $\mathrm{CdS}$ decorated 1D $\mathrm{ZnO}$ nanorods-2D graphene hybrids: low temperature synthesis and enhanced photocatalytic performance. Adv. Funct. Mater. 25, 221-229. doi: 10.1002/adfm.201402443

Han, C., Zhang, N., and Xu, Y. J. (2016). Structural diversity of graphene materials and their multifarious roles in heterogeneous photocatalysis. Nano Today 11, 351-372. doi: 10.1016/j.nantod.2016.05.008

Han, S., Hu, L., Liang, Z., Wageh, S., Al-Ghamdi, A. A., Chen, Y., et al. (2014). One-step hydrothermal synthesis of $2 \mathrm{D}$ hexagonal nanoplates of alpha$\mathrm{Fe}_{2} \mathrm{O}_{3}$ /graphene composites with enhanced photocatalytic activity. Adv. Funct. Mater. 24, 5719-5727. doi: 10.1002/adfm.201401279

He, J., Sun, H., Indrawirawan, S., Duan, X., Tade, M. O., and Wang, S. (2015). Novel polyoxometalate@g-C(3)N(4) hybrid photocatalysts for degradation of dyes and phenolics. J. Colloid Interface Sci. 456, 15-21. doi: 10.1016/j.jcis.2015.06.003

Hisatomi, T., Kubota, J., and Domen, K. (2014). Recent advances in semiconductors for photocatalytic and photoelectrochemical water splitting. Chem. Soc. Rev. 43, 7520-7535. doi: 10.1039/C3CS60378D

Hong, Y., Shi, P., Wang, P., and Yao, W. (2015). Improved photocatalytic activity of $\mathrm{CdS} /$ reduced graphene oxide (RGO) for $\mathrm{H}_{2}$ evolution by strengthening the connection between CdS and RGO sheets. Int. J. Hydrogen Energy 40, 7045-7051. doi: 10.1016/j.ijhydene.2015.04.005

Jia, L., Wang, D.-H., Huang, Y.-X., Xu, A.-W., and Yu, H.-Q. (2011). Highly durable N-Doped Graphene/CdS nanocomposites with enhanced 
photocatalytic hydrogen evolution from water under visible light irradiation. J. Phys. Chem. C 115, 11466-11473. doi: 10.1021/jp2023617

Jiang, Z., Wan, W., Wei, W., Chen, K., Li, H., Wong, P. K., et al. (2017). Gentle way to build reduced titanium dioxide nanodots integrated with graphite-like carbon spheres: from DFT calculation to experimental measurement. Appl. Catal. B 204, 283-295. doi: 10.1016/j.apcatb.2016.11.044

Jing, Y. Q., Gui, C. X., Qu, J., Hao, S. M., Wang, Q. Q., and Yu, Z. Z. (2017). Silver silicate@carbon nanotube nanocomposites for enhanced visible light photodegradation performance. Acs Sust. Chem. Eng. 5, 3641-3649. doi: $10.1021 /$ acssuschemeng.6b02650

Kim, H. I., Kim, S., Kang, J. K., and Choi, W. (2014). Graphene oxide embedded into $\mathrm{TiO}_{2}$ nanofiber: effective hybrid photocatalyst for solar conversion. $J$. Catal. 309, 49-57. doi: 10.1016/j.jcat.2013.08.028

Lee, J. S., You, K. H., and Park, C. B. (2012). Highly photoactive, low bandgap $\mathrm{TiO}_{2}$ nanoparticles wrapped by graphene. Adv. Mater. 24, 1084-1088. doi: 10.1002/adma.201104110

Lee, W. J., Lee, J. M., Kochuveedu, S. T., Han, T. H., Jeong, H. Y., Park, M., et al. (2012). Biomineralized $\mathrm{N}$-doped $\mathrm{CNT} / \mathrm{TiO}_{2}$ core/shell nanowires for visible light photocatalysis. ACS Nano 6, 935-943. doi: 10.1021/nn204504h

Li, K., Peng, B., and Peng, T. (2016). Recent advances in heterogeneous photocatalytic $\mathrm{CO}_{2}$ conversion to solar fuels. ACS Catal. 6, 7485-7527. doi: 10.1021/acscatal.6b02089

Li, Q., Guo, B., Yu, J., Ran, J., Zhang, B., Yan, H., et al. (2011). Highly efficient visible-light-driven photocatalytic hydrogen production of CdScluster-decorated graphene nanosheets. J. Am. Chem. Soc. 133, 10878-10884. doi: $10.1021 / \mathrm{ja} 2025454$

Li, Q., Li, X., Wageh, S., Al-Ghamdi, A. A., and Yu, J. (2015). CdS/Graphene nanocomposite photocatalysts. Adv. Energy Mater. 5:1500010. doi: 10.1002/aenm.201500010

Li, X., Yu, J., Wageh, S., Al-Ghamdi, A. A., and Xie, J. (2016). Graphene in photocatalysis: a review. Small 12, 6640-6696. doi: 10.1002/smll.201600382

Li, Z., Gao, B., Chen, G. Z., Mokaya, R., Sotiropoulos, S., and Puma, G. L. (2011). Carbon nanotube/titanium dioxide $\left(\mathrm{CNT} / \mathrm{TiO}_{2}\right)$ coreshell nanocomposites with tailored shell thickness, CNT content and photocatalytic/photoelectrocatalytic properties. Appl. Catal. B Environ. 110, 50-57. doi: 10.1016/j.apcatb.2011.08.023

Liu, J., Song, Y., Xu, H., Zhu, X., Lian, J., Xu, Y., et al. (2017). Non-metal photocatalyst nitrogen-doped carbon nanotubes modified mpg-C(3) $\mathrm{N}(4)$ :facile synthesis and the enhanced visible-light photocatalytic activity. J. Colloid Interface Sci. 494, 38-46. doi: 10.1016/j.jcis.2017.01.010

Liu, S. Q., Yang, M. Q., Zhang, N., and Xu, Y. J. (2014). Nanocomposites of graphene-CdS as photoactive and reusable catalysts for visiblelight-induced selective reduction process. J. Energy Chem. 23, 145-155. doi: 10.1016/S2095-4956(14)60129-7

Liu, Y., Ding, S., Xu, J., Zhang, H., Yang, S., Duan, X., et al. (2017b). Preparation of a p-n heterojunction $\mathrm{BiFeO}_{3} @ \mathrm{TiO}_{2}$ photocatalyst with a core-shell structure for visible-light photocatalytic degradation. Chin. J. Catal. 38, 1052-1062. doi: 10.1016/S1872-2067(17)62845-6

Ma, Y., Lu, N., Lu, Y., Guan, J. N., Qu, J., Liu, H. Y., et al. (2016). Comparative study of carbon materials synthesized "greenly" for 2-CP removal. Sci. Rep. 6:29167. doi: $10.1038 /$ srep29167

Martha, S., Padhi, D. K., and Parida, K. (2014). Reduced graphene oxide/InGaZn mixed oxide nanocomposite photocatalysts for hydrogen production. ChemSusChem 7, 585-597. doi: 10.1002/cssc.201300685

Matos, J., Laine, J., and Herrmann, J. M. (2001). Effect of the type of activated carbons on the photocatalytic degradation of aqueous organic pollutants by UV-irradiated titania. J. Catal. 200, 10-20. doi: 10.1006/jcat.2001.3191

Matsuoka, M., Kitano, M., Takeuchi, M., Tsujimaru, K., Anpo, M., and Thomas, J. M. (2007). Photocatalysis for new energy production. Catal. Today 122, 51-61. doi: 10.1016/j.cattod.2007.01.042

Ming, F. W., Hong, J. Q., Xu, X., and Wang, Z. C. (2016). Dandelionlike $\mathrm{ZnS} /$ carbon quantum dots hybrid materials with enhanced photocatalytic activity toward organic pollutants. RSC Adv. 6, 31551-31558. doi: 10.1039/C6RA02840C

Moniz, S. J. A., Shevlin, S. A., Martin, D. J., Guo, Z.-X., and Tang, J. (2015). Visiblelight driven heterojunction photocatalysts for water splitting-a critical review. Energy Environ. Sci. 8, 731-759. doi: 10.1039/C4EE03271C
Morales-Torres, S., Pastrana-Martinez, L. M., Figueiredo, J. L., Faria, J. L., and Silva, A. M. T. (2012). Design of graphene-based $\mathrm{TiO}_{2}$ photocatalysts-a review. Environ. Sci. Pollut. Res. 19, 3676-3687. doi: 10.1007/s11356-012-0939-4

Mukthar Ali, M., and Sandhya, K. Y. (2014). Visible light responsive titanium dioxide-cyclodextrin-fullerene composite with reduced charge recombination and enhanced photocatalytic activity. Carbon N.Y. 70, 249-257. doi: 10.1016/j.carbon.2014.01.003

Murcia-Lopez, S., Navio, J. A., and Hidalgo, M. C. (2013). Role of activated carbon on the increased photocatalytic activity of $\mathrm{AC} / \mathrm{Bi}_{2} \mathrm{WO}_{6}$ coupled materials. Appl. Catal. Gen. 466, 51-59. doi: 10.1016/j.apcata.2013.06.022

Murgolo, S., Petronella, F., Ciannarella, R., Comparelli, R., Agostiano, A., Curri, M. L., et al. (2015). UV and solar-based photocatalytic degradation of organic pollutants by nano-sized $\mathrm{TiO}_{2}$ grown on carbon nanotubes. Catal. Today 240, 114-124. doi: 10.1016/j.cattod.2014.04.021

Ng, Y. H., Ikeda, S., Matsumura, M., and Amal, R. (2012). A perspective on fabricating carbon-based nanomaterials by photocatalysis and their applications. Energy Environ. Sci. 5:9307. doi: 10.1039/c2ee22128d

Ouzzine, M., Romero-Anaya, A. J., Lillo-Ródenas, M. A., and Linares-Solano, A. (2014). Spherical activated carbon as an enhanced support for $\mathrm{TiO}_{2} / \mathrm{AC}$ photocatalysts. Carbon N. Y. 67, 104-118. doi: 10.1016/j.carbon.2013.09.069

Paulo, S., Palomares, E., and Martinez-Ferrero, E. (2016). Graphene and carbon quantum dot-based materials in photovoltaic devices: from synthesis to applications. Nanomaterials 6:157. doi: 10.3390/nano6090157

Peng, K. Q., Wang, X., Li, L., Hu, Y., and Lee, S. T. (2013). Silicon nanowires for advanced energy conversion and storage. Nano Today 8, 75-97. doi: 10.1016/j.nantod.2012.12.009

Peng, W. C., Chen, Y., and Li, X. Y. (2016). $\mathrm{MoS}_{2} /$ reduced graphene oxide hybrid with CdS nanoparticles as a visible light-driven photocatalyst for the reduction of 4-nitrophenol. J. Hazard. Mater. 309, 173-179. doi: 10.1016/j.jhazmat.2016.02.021

Peng, W. C., Wang, X., and Li, X. Y. (2014). The synergetic effect of $\mathrm{MoS}_{(2)}$ and graphene on $\mathrm{Ag}_{(3)} \mathrm{PO}_{(4)}$ for its ultra-enhanced photocatalytic activity in phenol degradation under visible light. Nanoscale 6, 8311-8317. doi: $10.1039 / \mathrm{c} 4 \mathrm{nr} 01654 \mathrm{~h}$

Peng, W., Li, Y., Zhang, F., Zhang, G., and Fan, X. (2017). Roles of two-dimensional transition metal dichalcogenides as cocatalysts in photocatalytic hydrogen evolution and environmental remediation. Ind. Eng. Chem. Res. 56, 4611-4626. doi: 10.1021 /acs.iecr.7b00371

Putri, L. K., Ong, W.-J., Chang, W. S., and Chai, S.-P. (2015). Heteroatom doped graphene in photocatalysis: a review. Appl. Surf. Sci. 358, 2-14. doi: 10.1016/j.apsusc.2015.08.177

Qi, K., Selvaraj, R., Al Fahdi, T., Al-Kindy, S., Kim, Y., Wang, G. C., et al. (2016). Enhanced photocatalytic activity of anatase- $\mathrm{TiO}_{2}$ nanoparticles by fullerene modification: a theoretical and experimental study. Appl. Surf. Sci. 387, 750-758. doi: 10.1016/j.apsusc.2016.06.134

Qiu, B., Xing, M., and Zhang, J. (2014). Mesoporous $\mathrm{TiO}_{2}$ nanocrystals grown in situ on graphene aerogels for high photocatalysis and lithium-Ion batteries. J. Am. Chem. Soc. 136, 5852-5855. doi: 10.1021/ja500873u

Ran, J., Zhang, J., Yu, J., Jaroniec, M., and Qiao, S. Z. (2014). Earth-abundant cocatalysts for semiconductor-based photocatalytic water splitting. Chem. Soc. Rev. 43, 7787-7812. doi: 10.1039/C3CS60425J

Ren, X., Yang, H., Gen, S., Zhou, J., Yang, T., Zhang, X., et al. (2016). Controlled growth of $\mathrm{LaFeO}_{3}$ nanoparticles on reduced graphene oxide for highly efficient photocatalysis. Nanoscale 8, 752-756. doi: 10.1039/C5NR06338H

Sampaio, M. J., Silva, C. G., Silva, A. M. T., Pastrana-Martinez, L. M., Han, C., Morales-Torres, S., et al. (2015). Carbon-based $\mathrm{TiO}_{2}$ materials for the degradation of Microcystin-LA. Appl. Catal. B-Environ. 170, 74-82. doi: 10.1016/j.apcatb.2015.01.013

Shearer, C. J., Cherevan, A., and Eder, D. (2014). Application and future challenges of functional nanocarbon hybrids. Adv. Mater. Weinheim. 26, 2295-2318. doi: 10.1002/adma.201305254

Shi, W., Lv, H., Yuan, S., Huang, H., Liu, Y., and Kang, Z. (2017). Synergetic effect of carbon dots as co-catalyst for enhanced photocatalytic performance of methyl orange on $\mathrm{ZnIn}_{2} \mathrm{~S}_{4}$ microspheres. Sep. Purif. Technol. 174, 282-289. doi: 10.1016/j.seppur.2016.11.013

Silva, C. G., Sampaio, M. J., Marques, R. R. N., Ferreira, L. A., Tavares, P. B., Silva, A. M. T., et al. (2015). Photocatalytic production of hydrogen from methanol 
and saccharides using carbon nanotube- $\mathrm{TiO}_{2}$ catalysts. Appl. Catal. B Environ. 178, 82-90. doi: 10.1016/j.apcatb.2014.10.032

Strobel, R., Garche, J., Moseley, P. T., Jorissen, L., and Wolf, G. (2006). Hydrogen storage by carbon materials. J. Power Sources 159, 781-801. doi: $10.1016 /$ j.jpowsour.2006.03.047

Tan, L. L., Chai, S. P., and Mohamed, A. R. (2012). Synthesis and applications of graphene-based $\mathrm{TiO}_{2}$ photocatalysts. ChemSusChem 5, 1868-1882. doi: $10.1002 /$ cssc.201200480

Thangavel, S., Krishnamoorthy, K., Kim, S. J., and Venugopal, G. (2016). Designing $\mathrm{ZnS}$ decorated reduced graphene-oxide nanohybrid via microwave route and their application in photocatalysis. J. Alloys Compd. 683, 456-462. doi: 10.1016/j.jallcom.2016.05.089

Tian, F., Wu, Z., Yan, Y., Ye, B. C., and Liu, D. (2016). Synthesis of visible-lightresponsive $\mathrm{Cu}$ and $\mathrm{N}$-Codoped $\mathrm{AC} / \mathrm{TiO}_{2}$ photocatalyst through microwave irradiation. Nanoscale Res. Lett. 11:292. doi: 10.1186/s11671-016-1503-9

Tian, J., Leng, Y., Zhao, Z., Xia, Y., Sang, Y., Hao, P., et al. (2015). Carbon quantum dots/hydrogenated $\mathrm{TiO}_{2}$ nanobelt heterostructures and their broad spectrum photocatalytic properties under UV, visible, and near-infrared irradiation. Nano Energy 11, 419-427. doi: 10.1016/j.nanoen.2014.10.025

Wang, C., Cao, M., Wang, P., and Ao, Y. (2013). Preparation, characterization of CdS-deposited graphene-carbon nanotubes hybrid photocatalysts with enhanced photocatalytic activity. Mater. Lett. 108, 336-339. doi: 10.1016/j.matlet.2013.06.102

Wang, H., Zhang, L., Chen, Z., Hu, J., Li, S., Wang, Z., et al. (2014). Semiconductor heterojunction photocatalysts: design, construction, and photocatalytic performances. Chem. Soc. Rev. 43, 5234-5244. doi: 10.1039/C4CS00126E

Wang, J., Wang, Z., and Zhu, Z. (2017). Synergetic effect of $\mathrm{Ni}(\mathrm{OH})_{2}$ cocatalyst and CNT for high hydrogen generation on CdS quantum dot sensitized $\mathrm{TiO}_{2}$ photocatalyst. Appl. Catal. B 204, 577-583. doi: 10.1016/j.apcatb.2016.12.008

Wang, X., Maeda, K., Thomas, A., Takanabe, K., Xin, G., Carlsson, J. M., et al. (2009). A metal-free polymeric photocatalyst for hydrogen production from water under visible light. Nat. Mater. 8, 76-80. doi: 10.1038/nmat2317

Weng, B., Liu, S. Q., Zhang, N., Tang, Z. R., and Xu, Y. J. (2014). A simple yet efficient visible-light-driven CdS nanowires-carbon nanotube 1D-1D nanocomposite photocatalyst. J. Catal. 309, 146-155. doi: 10.1016/j.jcat.2013.09.013

Woan, K., Pyrgiotakis, G., and Sigmund, W. (2009). Photocatalytic carbon-nanotube- $\mathrm{TiO}_{2}$ composites. Adv. Mater. 21, 2233-2239. doi: 10.1002/adma.200802738

Wu, X., Zhao, J., Wang, L., Han, M., Zhang, M., Wang, H., et al. (2017). Carbon dots as solid-state electron mediator for $\mathrm{BiVO}_{4} / \mathrm{CDs} / \mathrm{CdS} \mathrm{Z}$-scheme photocatalyst working under visible light. Appl. Catal. B 206, 501-509. doi: 10.1016/j.apcatb.2017.01.049

Xiang, Q. J., Yu, J. G., and Jaroniec, M. (2012). Graphene-based semiconductor photocatalysts. Chem. Soc. Rev. 41, 782-796. doi: 10.1039/C1CS15172J

Xie, G., Zhang, K., Guo, B., Liu, Q., Fang, L., and Gong, J. R. (2013). Graphenebased materials for hydrogen generation from light-driven water splitting. $A d v$. Mater. Weinheim. 25, 3820-3839. doi: 10.1002/adma.201301207

Xie, X. Q., Kretschmer, K., and Wang, G. X. (2015). Advances in graphenebased semiconductor photocatalysts for solar energy conversion: fundamentals and materials engineering. Nanoscale 7, 13278-13292. doi: 10.1039/C5NR 03338A

Xu, H., Wang, C., Song, Y. H., Zhu, J. X., Xu, Y. G., Yan, J., et al. (2014). $\mathrm{CNT} / \mathrm{Ag}_{3} \mathrm{PO}_{4}$ composites with highly enhanced visible light photocatalytic activity and stability. Chem. Eng. J. 241, 35-42. doi: 10.1016/j.cej.2013. 11.065

Xu, J., Wang, L., and Cao, X. (2016). Polymer supported graphene-CdS composite catalyst with enhanced photocatalytic hydrogen production from water splitting under visible light. Chem. Eng. J. 283, 816-825. doi: 10.1016/j.cej.2015.08.018

Yang, J. H., Wang, D. E., Han, H. X., and Li, C. (2013). Roles of cocatalysts in photocatalysis and photoelectrocatalysis. Accouts Chem. Res. 46, 1900-1909. doi: $10.1021 /$ ar300227e

Yang, M. Q., Zhang, N., and Xu, Y. J. (2013). Synthesis of fullerene-, carbon nanotube-, and graphene- $\mathrm{TiO}(2)$ nanocomposite photocatalysts for selective oxidation: a comparative study. ACS Appl. Mater. Interfaces 5, 1156-1164. doi: $10.1021 / \mathrm{am} 3029798$
Ye, A., Fan, W., Zhang, Q., Deng, W., and Wang, Y. (2012). CdSgraphene and CdS-CNT nanocomposites as visible-light photocatalysts for hydrogen evolution and organic dye degradation. Catal. Sci. Technol. 2:969. doi: 10.1039/c2cy20027a

Yu, H., Shi, R., Zhao, Y., Waterhouse, G. I. N., Wu, L. Z., Tung, C. H., et al. (2016), Smart utilization of carbon dots in semiconductor photocatalysis. Adv. Mater. 28, 9454-9477. doi: 10.1002/adma.201602581

Yu, H., Zhao, Y., Zhou, C., Shang, L., Peng, Y., Cao, Y., et al. (2014). Carbon quantum dots $/ \mathrm{TiO}_{2}$ composites for efficient photocatalytic hydrogen evolution. J. Mater. Chem. A 2:3344. doi: 10.1039/c3ta14108j

Yu, J., Jin, J., Cheng, B., and Jaroniec, M. (2014). A noble metal-free reduced graphene oxide-CdS nanorod composite for the enhanced visible-light photocatalytic reduction of $\mathrm{CO}_{2}$ to solar fuel. J. Mater. Chem. A 2:3407. doi: $10.1039 / \mathrm{c} 3 \mathrm{ta} 14493 \mathrm{c}$

Yu, J., Yang, B., and Cheng, B. (2012). Noble-metal-free carbon nanotube$\mathrm{Cd}_{0.1} \mathrm{Zn}_{0.9} \mathrm{~S}$ composites for high visible-light photocatalytic $\mathrm{H}_{2}$-production performance. Nanoscale 4, 2670-2677. doi: 10.1039/c2nr30129f

Yue, Z. K., Liu, A. J., Zhang, C. Y., Huang, J., Zhu, M. S., Du, Y. $\mathrm{K}$, et al. (2017). Noble-metal-free hetero-structural $\mathrm{CdS} / \mathrm{Nb}_{2} \mathrm{O}_{5} / \mathrm{N}$ doped-graphene ternary photocatalytic system as visible-light-driven photocatalyst for hydrogen evolution. Appl. Catal. B-Environ. 201, 202-210. doi: 10.1016/j.apcatb.2016.08.028

Zarezade, M., Ghasemi, S., and Gholami, M. R. (2011). The effect of multiwalled carbon nanotubes and activated carbon on the morphology and photocatalytic activity of $\mathrm{TiO}_{2} / \mathrm{C}$ hybrid materials. Catal. Sci. Technol. 1, 279-284. doi: $10.1039 / \mathrm{c} 0$ cy00042f

Zeng, X., Wang, Z., Meng, N., McCarthy, D. T., Deletic, A., and Pan, J. H., et al. (2017). Highly dispersed $\mathrm{TiO}_{2}$ nanocrystals and carbon dots on reduced graphene oxide: Ternary nanocomposites for accelerated photocatalytic water disinfection. Appl. Catal. B 202, 33-41. doi: 10.1016/j.apcatb.2016. 09.014

Zhang, D., Hu, B., Guan, D., and Luo, Z. (2016a). Essential roles of defects in pure graphene/ $\mathrm{Cu}_{2} \mathrm{O}$ photocatalyst. Catal. Commun. 76, 7-12. doi: 10.1016/j.catcom.2015.12.013

Zhang, K., and Guo, L. (2013). Metal sulphide semiconductors for photocatalytic hydrogen production. Catal. Sci. Technol. 3:1672. doi: 10.1039/c3cy00018d

Zhang, L., Fu, X., Meng, S., Jiang, X., Wang, J., and Chen, S. (2015a). Ultralow content of Pt modified CdS nanorods: one-pot synthesis and high photocatalytic activity for $\mathrm{H}_{2}$ production under visible light. J. Mater. Chem. A 3, 23732-23742. doi: 10.1039/C5TA07459B

Zhang, N., Yang, M. Q., Tang, Z. R., and Xu, Y. J. (2013a). CdS-graphene nanocomposites as visible light photocatalyst for redox reactions in water: a green route for selective transformation and environmental remediation. $J$. Catal. 303, 60-69. doi: 10.1016/j.jcat.2013.02.026

Zhang, N., Zhang, Y. H., and Xu, Y. J. (2012). Recent progress on graphene-based photocatalysts: current status and future perspectives. Nanoscale 4, 5792-5813. doi: $10.1039 / \mathrm{c} 2 \mathrm{nr} 31480 \mathrm{k}$

Zhang, N., Zhang, Y., Yang, M. Q., Tang, Z. R., and Xu, Y. J. (2013b). A critical and benchmark comparison on graphene-, carbon nanotube-, and fullerenesemiconductor nanocomposites as visible light photocatalysts for selective oxidation. J. Catal. 299, 210-221. doi: 10.1016/j.jcat.2012.11.021

Zhang, P., Wang, T., and Gong, J. (2015b). Mechanistic understanding of the plasmonic enhancement for solar water splitting. Adv. Mater. Weinheim. 27, 5328-5342. doi: 10.1002/adma.201500888

Zhang, X. H., Peng, T. Y., and Song, S. S. (2016b). Recent advances in dyesensitized semiconductor systems for photocatalytic hydrogen production. J. Mater. Chem. A 4, 2365-2402. doi: 10.1039/C5TA08939E

Zhang, Y., Tang, Z.-R., Fu, X., and Xu, Y.-J. (2011). Engineering the Unique 2D Mat of Graphene to Achieve Graphene- $\mathrm{TiO}_{2}$ Nanocomposite for Photocatalytic selective transformation: what advantage does graphene have over its forebear carbon nanotube? ACS Nano 5, 7426-7435. doi: 10.1021/ $\mathrm{nn} 202519 \mathrm{j}$

Zhang, Y. H., Tang, Z. R., Fu, X. Z., and Xu, Y. J. (2010). $\mathrm{TiO}_{2}-$ graphene nanocomposites for gas-phase photocatalytic degradation of volatile aromatic pollutant: is $\mathrm{TiO}_{2}$-graphene truly different from other $\mathrm{TiO}_{2}$-carbon composite materials? ACS Nano 4, 7303-7314. doi: 10.1021/ nn1024219 
Zhong, Y., Zhao, G., Ma, F., Wu, Y., and Hao, X. (2016). Utilizing photocorrosion-recrystallization to prepare a highly stable and efficient $\mathrm{CdS} / \mathrm{WS}_{2}$ nanocomposite photocatalyst for hydrogen evolution. Appl. Catal. B 199, 466-472. doi: 10.1016/j.apcatb.2016.06.065

Zhou, X. F., Li, X., Gao, Q. Z., Yuan, J. L., Wen, J. Q., Fang, Y. P., et al. (2015). Metal-free carbon nanotube-SiC nanowire heterostructures with enhanced photocatalytic $\mathrm{H}_{2}$ evolution under visible light irradiation. Catal. Sci. Technol. 5, 2798-2806. doi: 10.1039/C4CY01757A

Zou, X., and Zhang, Y. (2015). Noble metal-free hydrogen evolution catalysts for water splitting. Chem. Soc. Rev. 44, 5148-5180. doi: 10.1039/C4CS00448E
Conflict of Interest Statement: The authors declare that the research was conducted in the absence of any commercial or financial relationships that could be construed as a potential conflict of interest.

Copyright (c) 2017 Han, Li, Li, Fan, Zhang, Zhang and Peng. This is an open-access article distributed under the terms of the Creative Commons Attribution License (CC $B Y)$. The use, distribution or reproduction in other forums is permitted, provided the original author(s) or licensor are credited and that the original publication in this journal is cited, in accordance with accepted academic practice. No use, distribution or reproduction is permitted which does not comply with these terms. 